\title{
Oxidative Stress Mechanisms in the Pathogenesis of Environmental Lung Diseases
}

\author{
Rajesh K. Thimmulappa, Indranil Chattopadhyay, \\ and Subbiah Rajasekaran
}

\begin{abstract}
Globally, respiratory diseases are major cause of disability and mortality, and more alarmingly, it disproportionately affects developing countries, which is largely attributed to poor quality of air. Tobacco smoke and emissions from combustion of fossil fuel and biomass fuel are the major airborne pollutants affecting human lung health. Oxidative stress is the dominant driving force by which the airborne pollutants exert their toxicity in lungs and cause respiratory diseases. Most airborne pollutants are associated with intrinsic oxidative potential and, additionally, stimulate endogenous production of reactive oxygen species (ROS) and reactive nitrogen species (RNS). Elevated ROS and RNS in lungs modulate redox signals and cause irreversible damage to critical biomolecules (lipids, proteins and DNA) and initiate various pathogenic cellular process. This chapter provides an insight into oxidative stress-linked pathogenic cellular process such as lipid peroxidation, inflammation, cell death, mitochondrial dysfunction, endoplasmic reticulum stress, epigenetic changes, profibrotic signals and mucus hypersecretion, which drive the development and progression of lung diseases. Lungs are associated with robust enzymatic and non-enzymatic (GSH, ascorbic acid, uric acid, vitamin E) antioxidant defences. However, sustained production of free radicals due to continuous exposures to airborne pollutants overwhelms lung antioxidant defences and causes oxidative injury. Preclinical studies have
\end{abstract}

\footnotetext{
R. K. Thimmulappa $(\bowtie)$

Department of Biochemistry, JSS Medical College, JSS Academy of Higher Education \& Research, Mysore, Karnataka, India e-mail: rajeshkt@jssuni.edu.in

I. Chattopadhyay

Department of Life Sciences, Central University of Tamil Nadu, Thiruvarur, Tamil Nadu, India
}

\author{
S. Rajasekaran \\ Department of Biotechnology, BIT-Campus, Anna University, Tiruchirappalli, India
}


demonstrated the critical roles and therapeutic potential of upregulating lung antioxidants for intervention of respiratory diseases; however, so far clinical benefits in antioxidant supplementation trials have been minimal and conflicting. Antioxidants alone may not be effective in treatment of respiratory diseases; however it could be a promising adjunctive therapy.

\section{Keywords}

Respiratory diseases $\cdot$ Oxidative stress $\cdot$ Lipid peroxidation $\cdot$ Inflammation $\cdot$ Cell death - Mitochondrial dysfunction - Endoplasmic reticulum stress · Epigenetic changes $\cdot$ Profibrotic signals $\cdot$ Mucus hypersecretion $\cdot$ Lung antioxidants

\subsection{Introduction}

With growing industrialization and rapid urbanization, the global burden of respiratory diseases is rising at an alarming rate and is a major source of disability and death following cardiovascular diseases [1,2]. Globally, around $10 \%$ of all disability-adjusted life years (DALYs) lost is attributed to respiratory illnesses mainly chronic obstructive pulmonary disease (COPD), asthma, tuberculosis, lower respiratory tract infection and lung cancer [3]. Respiratory diseases disproportionately affect developing countries [1,2], which is largely attributed to poor quality of air, although socioeconomic and genetic factors contribute significantly. Despite being so widespread, environmental respiratory illnesses are highly preventable.

Lungs are at the direct interface between body and the environment, and therefore, the major threat to lung health is the air we breathe. An adult individual inhales on average 10,000 to 15,000 litres of air every day. Inhaled oxygen along with airborne pollutants dissolves in respiratory epithelial lining fluid. The common pollutants that contaminate air include tobacco smoke, particulate matter, biomass fuel smoke, industrial emissions, ozone, oxides of nitrogen, oxides of sulphur and carbon monoxide. Most of these airborne pollutants are associated with intrinsic oxidative potential, and hence, oxidative stress is thought to be a dominant mechanism by which the air pollutants exert their toxicity in lungs. Several studies have reported elevated oxidatively damaged biomolecules in the exhaled breath condensate, nasal lavage, bronchoalveolar lavage and blood of human subjects following acute exposures to airborne pollutants such as cigarette smoke, ozone or particulate matter. Prolonged exposures to these airborne toxicants also stimulate endogenous cellular production of free radicals by diverse mechanisms including mitochondrial, NADPH oxidase, xanthine oxidase and myeloperoxidase activity. To defend against oxidative insult, lungs are endowed with powerful extracellular antioxidants in respiratory tract lining fluid as well as intracellular antioxidant defences. Measures to improve the air quality that we breathe and understanding the underlying mechanisms of disease development caused by exposures to airborne toxicants are pivotal to reduce the global burden 
of respiratory disease. This chapter chronicles the key mechanisms by which oxidative stress mediates development and progression of respiratory diseases. The chapter begins with an overview and sources of free radicals in the lungs and a brief description of key environmental respiratory diseases mainly COPD, asthma, acute respiratory distress syndrome and idiopathic pulmonary fibrosis. Finally, the chapter reviews the antioxidants associated with lungs and clinical studies testing antioxidant therapy for treatment of respiratory diseases.

\subsection{Sources of Free Radicals in Lungs}

\subsubsection{Free Radicals: ROS and RNS}

Free radical is a highly reactive chemical species, which interacts and damages cellular biomolecules (proteins, lipids, DNA and carbohydrates). Free radicals are molecules associated with an unpaired electron in their valency shell, which renders them intrinsically unstable and reactive. In biological systems, free radicals are oxygen-centred radicals and nitrogen-containing radicals collectively called as reactive oxygen species (ROS) and reactive nitrogen species (RNS), respectively. ROS comprises of radical species (such as superoxide, hydroxyl radicals, lipidderived hydroperoxides) and non-radical species (singlet oxygen, hydrogen peroxide and hypochlorous acid and ozone) (Table 5.1) [4, 5]. RNS includes nitric oxide, nitrogen dioxide, nitroxyl anion and peroxynitrite [6]. Elevated cellular levels of ROS and RNS with reduced capacity to detoxify or neutralize them or its derivatives result in a state of oxidative and nitrative stress, respectively.

Low levels of ROS and RNS function as secondary messengers and play a pivotal role in redox cell signalling and regulate diverse beneficial normal physiological processes such as bacterial killing during phagocytosis, vasodilation, tissue repair and regeneration $[4,7,8]$. In contrast, higher levels of ROS/RNS inflict irreversible damage to biomolecules resulting in cell and tissue injury, and if unchecked, it results in onset of inflammatory diseases including respiratory disease [9-11].

Table 5.1 List of ROS and RNS

\begin{tabular}{l|l}
\hline ROS & RNS \\
\hline Superoxide $\left(\mathrm{O}_{2} \cdot\right)$ & Nitric oxide $(\mathrm{NO})$ \\
\hline Hydrogen peroxide $\left(\mathrm{H}_{2} \mathrm{O}_{2}\right)$ & Nitrogen dioxide $\left(\mathrm{NO}_{2}\right)$ \\
\hline Hydroxyl radical $(\mathrm{HO})$ & Nitrous acid $\left(\mathrm{HNO}_{2}\right)$ \\
\hline Peroxyl radical $\left(\mathrm{RO}_{2}\right)$ & Dinitrogen tetroxide $\left(\mathrm{N}_{2} \mathrm{O}_{4}\right)$ \\
\hline Alkoxyl radical $(\mathrm{RO})$ & Dinitrogen trioxide $\left(\mathrm{N}_{2} \mathrm{O}_{3}\right)$ \\
\hline Hydroperoxyl radical $\left(\mathrm{HO}_{2}\right)$ & Peroxynitrite $(\mathrm{ONOO}-)$ \\
\hline Singlet oxygen $\left({ }^{1} \mathrm{O}_{2}\right)$ & Peroxynitrous acid $(\mathrm{ONOOH})$ \\
\hline Ozone $\left(\mathrm{O}_{3}\right)$ & Alkyl peroxynitrites $(\mathrm{ROONO})$ \\
\hline
\end{tabular}




\subsubsection{Sources of ROS and RNS in Lungs}

\subsubsection{Endogenous Sources of ROS/RNS in Lungs}

The endogenous source refers to free radicals produced by cells. Adult lung comprises around 40 different cell types [12], which can be broadly classified as epithelial, endothelial and neuroendocrine cells, smooth muscles, fibroblasts and immune cells (macrophages, neutrophils and T cells). All these cells have varied intrinsic capacity to generate ROS upon stimulation. In general, ROS/RNS are produced as intermediates or byproducts of cellular metabolism catalysed by enzymes localized in different organelles primarily plasma membrane, cytosol, mitochondria, peroxisomes and endoplasmic reticulum. The key enzymes that produce ROS/RNS in lungs include cytochrome c oxidase, NADPH oxidase, myeloperoxidase, xanthine oxidase and nitric oxidase synthase. In most of the lung disorders, the mitochondria are primary source of excess ROS $[4,9,13]$. Superoxide produced by mitochondria is a result of incomplete reduction of oxygen to water due to leakage of electrons by mitochondrial respiratory chain $[4,13]$. NADPH oxidase (NOX) is a multicomponent transmembrane enzyme complex that generates superoxide as end product via one electron reduction of oxygen [8-11]. In humans, there are seven isoforms of NOX - NOX1, NOX2, NOX3, NOX4, NOX5, DUOX1 and DUOX2. Nox2 is localized in phagosome of phagocytes (macrophages and neutrophils) and produces massive ROS to kill the phagocytized bacteria. NOX1, NOX2, NOX4, DUOX1 and DOUX2 are distributed in various cell types in the human lung [10, 14]. Myeloperoxidase (MPO), a heme-containing enzyme, is localized in lysosomes of neutrophils and macrophages [11] and catalyses chlorination of $\mathrm{H}_{2} \mathrm{O}_{2}$ to $\mathrm{HOCl}$, a highly reactive radical [11]. Additionally, MPO catalyses oxidation of thiocyanate to generate hypothiocyanite. Xanthine oxidase, localized in the plasma membrane and cytosol, catalyses oxidation of hypoxanthine to xanthine and to uric acid, during which superoxide is generated $[6,15]$. The enzyme nitric oxide synthase catalyses oxidation of L-arginine to citrulline and nitric oxide $[7,16]$. Nitric oxide produced reacts with superoxide to form very potent RNS intermediate, peroxynitrite $\left(\mathrm{OONO}^{-}\right)$. There are three isoforms of NOS, namely, NOSI (neuronal NOS, nNOS), NOS2 (endothelial NOS, eNOS) and NOS3 (inducible NOS, iNOS). Pulmonary cells constitutively express NOS1 and NOS2, while NOS3 is elevated in the lung during inflammation $[7,16,17]$.

\subsubsection{ROS and RNS in Lungs: Exogenous Sources}

Inhalation of airborne toxicants such as tobacco smoke, biomass fuel smoke, particulate matter and gaseous emissions (nitrogen oxides and sulphur oxides), ozone, chemical toxins, pesticides and pollen grains largely constitutes the exogenous sources of oxidants in lungs [18]. Among the airborne toxicants, ambient air pollution particulate matter and cigarette smoke are the main contributors of free radicals 
in human lungs $[1,3,19,20]$. Depending on the size, the ambient particulate matter (PM) exhibits different physicochemical properties [21, 22]. Coarse particles larger than 10 microns are composed of natural materials (mineral and silicates) and are trapped and cleared by the nose and upper respiratory tract [23, 24]. Fine PM of size 2.5 microns $\left(\mathrm{PM}_{2.5}\right)$ and lesser and ultrafine particles $(<0.1$ microns $)$ are produced by the combustion process from anthropogenic activities and are composed of polycyclic aromatic hydrocarbons (PAH), metals, minerals, sulphates and nitrates [23, 25]. $\mathrm{PM}_{2.5}$ and ultrafine particles could reach deep into distal lungs and cause injury to the alveoli [24]. A single puff of cigarette smoke comprises of $10^{15}$ free radicals $[20,26]$ and over 4000 chemicals including epoxides, peroxides, semiquinones, quinones and PAH. The cigarette smoke free radicals are classified into two phases: $\operatorname{tar}$ (particle) and gas. Tar phase has $10^{17}$ relatively long-lived radical molecules per gram such as quinone/hydroquinone $(\mathrm{Q} / \mathrm{QH} 2)$ radicals, which produce $\mathrm{O}_{2}{ }^{-{ }^{-}}$leading to the generation of $\mathrm{H}_{2} \mathrm{O}_{2}$ and $\bullet \mathrm{OH}$ [27]. Gas phase of cigarette smoke comprises of $10^{15}$ organic and inorganic radicals per puff and includes NO•, NOx and ONOO[28]. Ozone is another powerful exogenous oxidant in the lungs [29]. Plant pollens are associated with NADPH oxidase enzyme and are shown to generate superoxide in the airways following inhalation. Besides possessing intrinsic oxidative potential, the airborne toxicants also stimulate production of ROS by activating NADPH oxidase, damaging mitochondria and by recruitment of inflammatory cells (macrophages and neutrophils).

\subsection{Oxidative Stress-Associated Pulmonary Disorders}

\subsubsection{Chronic Obstructive Pulmonary Disease (COPD)}

As per the recent estimates by a global burden of disease study [1], COPD kills over three million people and is the third leading cause of death. COPD is characterized by progressive, irreversible limitation in expiratory airflow and abnormal lung inflammation. The disease process involves airway inflammation and remodeling, mucus hypersecretion, loss of the terminal bronchioles and destruction of the lung parenchyma [30, 31]. Tobacco smoking is the primary causal agent of COPD; however, recent epidemiological evidence suggests that exposures to indoor and outdoor air pollutants are also a major etiological factor, especially in developing countries. Genetic polymorphisms in genes coding for alpha-1 antitrypsin, metalloproteinase 33 , superoxide dismutase-3 (SOD3) and tumour necrosis factor- $\alpha$ (TNF $\alpha$ ) are additional risk factors in $10 \%-20 \%$ of the smokers for developing COPD [32-37]. Although the underlying pathophysiological mechanisms are complex, the lungs of patient with COPD show persistent oxidative stress, increased levels of proinflammatory cytokines, increased CD4 and CD8 cells, elevated levels of proteases and increased apoptosis and senescence [38-44]. Oxidative stress-driven mechanisms are strongly implicated in the initiation and progression of COPD [45]. 


\subsubsection{Asthma}

Asthma is a very common airway disorder affecting both children and adults worldwide. Clinically, asthmatics show airway hyperresponsiveness, reversible airflow obstruction and abnormal airway inflammation [46]. Genetic factors in the combination of environmental exposures increase the risk of asthma. The common environmental agents that trigger asthma include aeroallergens (indoor and outdoor), tobacco smoke, dust, air pollutants, cold air and viruses. The hallmark pathological features of asthmatic airways include airway remodeling, epithelial desquamation, goblet cell hyperplasia and inflammation and are associated with eosinophils, mast cells, neutrophils, macrophages and T helper type 2 cells (Th2 cells) [47]. In asthmatics lungs, allergen exposure triggers immunoglobulin $\mathrm{E}(\mathrm{IgE})$ production from B cells, degranulation of mast cells and infiltration of eosinophil into airways. These events are mediated by Th2 cytokines, namely, IL-13, IL-4, IL-5 and IL-9. Th1 cytokines (IFN-g, IL-12) and Th17 cytokines (IL-23) are implicated in severe or steroid resistance asthma, which is characterized by high neutrophilic inflammation. ROS through direct injury to airway epithelial cells and via redox signalling mechanism are shown to enhance sensitivity to allergens and augment Th2/Th1 cytokine secretion and, therefore, intricately involved in the pathogenesis of asthma [48].

\subsubsection{Acute Respiratory Distress Syndrome (ARDS)}

Acute lung injury and its severe form ARDS are common complications in patients admitted to intensive care unit. ARDS results from direct or indirect injury to lungs. Direct injury may be caused by gastric aspiration, pneumonia, inhalation of injuries gases and pulmonary contusion. Indirect injury includes sepsis, pancreatitis and trauma. ARDS is characterized by alveolar flooding with protein-rich oedema followed by a progressive fibrotic phase [49]. Death among the patients with ARDS is mainly due to respiratory failure and/or multiorgan failure. Pathogenesis of ARDS involves an early injury to alveolar epithelium and capillary endothelium, which results in leakage and flooding of alveolar and interstitial spaces with protein-rich oedema. This is also accompanied by a massive influx of neutrophils into alveolar and interstitial spaces. Neutrophils secrete proteolytic enzymes (elastase and metalloprotease), ROS, proinflammatory mediators and further lung injury [50]. The early inflammatory exudative phase is followed by a fibroproliferative phase in which fibroblast and myofibroblast infiltrate and proliferate within the alveolar and interstitial spaces leading to lung fibrosis [51]. Oxidative stress is shown to mediate epithelial-endothelial barrier dysfunction and perpetuate inflammation in ARDS patients $[52,53]$. 


\subsubsection{Idiopathic Pulmonary Fibrosis (IPF)}

IPF is a progressive interstitial pulmonary fibrosis disorder with no known causal etiological factor. The lungs of patients with IPF show excessive deposition of matrix proteins such as fibronectin and collagen in the alveoli and lung parenchyma, which destroys the gas exchange surface leading to respiratory failure [54]. It is more prevalent in the USA and Europe than South America and South Asia. IPF disproportionately affects individuals above age 65 years, and often it is referred to as age-related disorder. Pathogenesis of IPF involves chronic insult to alveolar epithelial cells (AEC), senescence of AEC and fibroblast, increased differentiation of fibroblast to myofibroblast [54] and increased accumulation of myofibroblast, which is mediated by oxidative injury, mitochondrial dysfunction, proteotoxicity and endoplasmic reticulum stress $[14,55]$. Emerging evidences implicate ROS by Nox4 as a key player in the pathogenesis of IPF [55].

\subsection{Oxidative Stress-Driven Mechanisms in Lung Diseases}

\subsubsection{Oxidative Stress and Lipid Peroxidation}

Lipid peroxidation (LPO) in biological systems refers to the oxidation of cellular membrane lipids; and uncontrolled LPO is the most significant early biological process induced by oxidative stress state. Excess LPO results in defective or dead cell, inactivation of critical proteins and activation of proinflammatory responses. Together, these events not only initiate but also ensue disease progression. Numerous studies have overwhelmingly showed that LPO is a universal pathogenic event in all the respiratory diseases including COPD, IPF, ARDS and asthma [56].

Membrane lipids mainly glycerophospholipids (PL) esterified with polyunsaturated fatty acid (PUFA) and to a lesser extent free PUFA are the targets for oxidation. Free PUFAs released by action of phospholipases inside the cells are substrates for enzymes such as cyclooxygenase, lipoxygenase and cytochrome P450s, and hence, free PUFA undergoes enzyme-dependent peroxidation. PL-PUFAs are predominantly oxidized by non-enzymatic process and highly depend on the radical species. Both radical species ( $\mathrm{OH}$ and $\left.\mathrm{O}_{2}^{-}{ }_{2}\right)$ and non-radical species $\left(\mathrm{H}_{2} \mathrm{O}_{2}, \mathrm{HOCl}\right.$, ozone and singlet oxygen) may oxidize PL-PUFA in selective or non-selective manner. The chemical reactions mediating the oxidation of PL-PUFA or free PUFA are similar; however, the products generated may vary. LPO process involves three phases - initiation, propagation and termination. During the initiation phase, nonradical lipid molecule becomes a lipid radical. The radical species abstract hydrogen from bisallylic methylene and produce a carbon-centred radical $\left(\mathrm{L}^{\circ}\right)$ within PUFA, which subsequently reacts with molecular oxygen and forms lipid peroxyl (LOO*) radical. During the propagation phase, the LOO ${ }^{\circ}$ radical abstracts hydrogen from bisallylic methylene of another PUFA molecule and transforms itself into a lipid hydroperoxide and, concomitantly, generates a new $\mathrm{L}^{\cdot}$ radical, and in this manner, the peroxidation chain reaction sustains. During termination process, 
antioxidant molecule, such as vitamin E, donates hydrogen, reduces lipid radicals without transforming itself into radical and thus terminates the LPO chain reaction. Lipid hydroperoxides may further participate in additional oxidative reactions such as Fenton reaction catalysed by $\mathrm{Fe}$ or $\mathrm{Cu}$, intra- and intermolecular oxidative modification and oxidative fragmentation. Finally, LPO produces diverse reactive aldehyde byproducts including widely studied malondialdehyde (MDA) and 4-hydroxy-2-nonenal (4HNE). The oxidation of PL-PUFA also yields diverse species of oxidized phospholipids (Ox-PLs) (aldehyde, alkene, peroxyl and alkane derivatives), which exhibit varying carbon chain length, hydrophobicity, reactivity, physical stability and biological activity [57]. The oxidized PUFA chain of glycerophospholipid may be released by the action of enzymes such as phospholipase A2 and PAF-acetyl hydrolases [57]. Since the cell membranes are composed of 40-50\% of phosphocholine (PC) phospholipids, PC-derived Ox-PLs species are the most abundant Ox-PLs detected in injured lungs.

LPO products such as MDA, 4HNE and Ox-PLs produced in the lungs are not bystanders; rather they actively take part in the pathogenesis of lung disease by inducing cell death, epithelial-endothelial barrier dysfunction, inflammation and immune responses [58]. Ox-PLs and 4HNE are shown to mediate cytotoxicity through disruption of membrane integrity and activating cell death signalling programs such as apoptosis [59, 60] and ferroptosis [61, 62]. Ox-PLs generated following particulate matter exposure caused disruption of the endothelial barrier [62]. Ox-PLs are demonstrated to be dominant mediators of acute lung injury following gastric aspiration and viral infection [63].

A large body of evidence has reported elevated levels of MDA, 4HNE or Ox-PLs or their corresponding protein adducts in the bronchoalveolar lavage fluid, lung tissue and/or serum of patients with various lung diseases such as asthma, COPD, ARDS and IPF [43, 64-66]. Immunohistochemical analysis revealed greater accumulation of 4HNE in the airways, alveolar epithelium and inflammatory cells of the lungs of COPD patient when compared to smoker non-COPD patient with similar smoking history [67]. The bronchoalveolar lavage fluid from COPD patients shows higher levels of Ox-PLs when compared to healthy subjects [43, 64, 65]. The lung parenchyma of IPF patients showed greater accumulation of LPO products $[54,55$, 68]. In most respiratory diseases, the levels of LPO byproducts increased with the severity of the pulmonary diseases, which suggest that the LPO is the central pathological event.

\subsubsection{Oxidative Stress in Activating Inflammatory Response}

It is proven beyond doubt that oxidative stress is involved in the initiation, promotion and augmentation of inflammation by affecting multiple redox-sensitive signal transduction pathways, including Toll-like receptor (TLR) signalling, MAPK kinase signalling and inflammasome which ultimately leads to activation of proinflammatory transcription factors particularly nuclear factor kappa-light-chain-enhancer of activated B cells (NF- $\mathrm{BB})$ and AP-1 [32, 69]. 
TLR signalling is central in activating pulmonary inflammatory responses following infectious stress and oxidative stress [70]. During infection, TLRs recognize highly conserved microbial motifs referred to as pathogen-associated molecular pattern (PAMP) and activate downstream inflammatory signals [71]. In mammals, there are 13 TLRs, which are present either on the plasma membrane (TLR1, TLR2, TLR4, TLR5, TLR6 and TLR10) or in endosome compartment (TLR3, TLR7, TLR8, TLR9) inside the cell. Upon activation by PAMPs, TLRs undergo hetero- or homodimer and trigger a downstream signal transduction by recruiting adaptor molecules, myeloid differentiation factor 88 (MYD88) or Toll-receptor-associated activator of interferon (TRIF). Except TLR3, a majority of TLRs recruit MYD88 that interacts with IRAK4 and phosphorylate IRAK1. Phosphorylated IRAK1 activates TNFR-associated factor 6 (TRAF6) through phosphorylation, which subsequently stimulates protein kinase $\mathrm{C}$ and transforming growth factor (TGF)- $\beta$-activated kinase 1 (TAK1). Activated TAK1 activates IKK complex and MAPK kinase family members (ERK1/2, p38 MAPK and c-Jun terminal kinase (JNK)) by phosphorylation mechanisms. TLR3 recruits adaptor molecule TRIF and activate TRAF3, which then activates TANK-binding kinase 1 (TBK1). Activated TBK1 initiates interferon regulatory factor 3 to transcribe IFN-beta cytokine which by autocrine or paracrine mechanism elicits interferon signalling pathway activation.

Transcription factor NF- $\mathrm{kB}$ is a central node in regulating inflammation leading to the pathogenesis of COPD, asthma, ARDS and IPF. NF- $\mathrm{KB}$ family is constituted

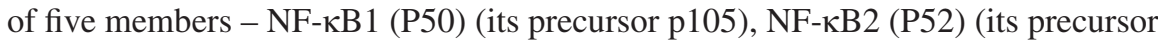
p100), p65/RelA, RelB and C-Rel - and exists as homo- or heterodimer. Only p65, Rel-B and C-Rel members have a transactivating domain. In an unstimulated cell, the NF- $\mathrm{kB}$ dimmer is sequestered in the cytoplasm by one of the three members of I $\kappa \mathrm{B}$ protein complex consisting of I $\mathrm{B} \alpha, \mathrm{I} \kappa \mathrm{B} \beta$ and $\mathrm{I} \kappa \mathrm{B} \varepsilon$. Activation of NF- $\kappa \mathrm{B}$ may occur through canonical or noncanonical pathways. In canonical pathway, signals elicited by TLR(s) ligands, TNF $\alpha$ or IL- $1 \beta$ converge at IкK complex constituted of

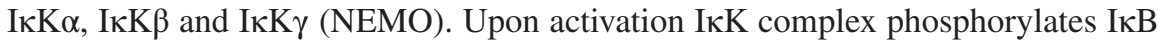
on serine 32 and serine 36 , which results in its proteasomal degradation and subsequently allows NF- $\kappa B$ to translocate into the nucleus. NF- $\kappa B$ binds to $\kappa B$ element in the promoter/enhancer regions and activates transcriptional expression of cytokines, chemokines and adhesion molecules, which are involved in coordinating innate and adaptive immunity [70-72].

Oxidative stress regulates activation of TLR signalling by multiple mechanisms [70]. NADPH oxidase-dependent ROS production is shown to enhance surface trafficking of TLR4 to lipid rafts, thereby augmenting downstream signals leading to hyperactivation of NF-kB [72-75]. Suppression of ROS generation by pharmacological NADPH oxidase inhibitor, genetic ablation of NADPH oxidase or exogenous antioxidants mitigated lipopolysaccharide (LPS)-induced TLR4 trafficking to lipid rafts and diminished downstream inflammatory responses [74, 75]. Genetic ablation of NADPH oxidase dampened lung inflammation and injury in mice exposed to gram-negative bacteria, LPS, TNF $\alpha$ or bleomycin, suggesting a crucial impact of NADPH oxidase-elicited ROS in producing inflammation and associated tissue injury [55, 74, 76-78]. On the other hand, ROS derived from NADPH oxidase 
have also been involved in the resolution of lung inflammation [79]. Mitochondriaderived ROS also play a crucial role in enhancing TLR1, TLR2 and TLR4 signalling [80] and production of proinflammatory cytokines [81]. ROS is shown to augment TLR3 signalling partly by increasing the expression of TLR3 [82]. Oxidatively damaged biomolecules also act as danger-associated molecular patterns (DAMPs) and engage TLR4 to activate inflammatory responses. For instance, oxidized phospholipids generated in lungs following exposures to chemicals, bacteria or virus act as DAMPs and activate TLR4 directed inflammatory responses [83], which is shown to play an essential role in the initiation of acute lung injury. In contrast, excess oxidized phospholipids may also dampen TLR4 signalling by directly interacting with LPS-binding protein, CD14 and/or MD-2 and inhibit inflammation and protect from sepsis [84]. Often oxidative or nitrosative modification of proteins gives rise to modified proteins, which act as DAMPs and perpetuate inflammation. For example, protein adducts of 4HNE or MDA are shown to elicit inflammatory and immune responses $[85,86]$ in the lungs. 4HNE has also been shown to activate NF- $\mathrm{KB}$ and p38 MAPK and promote inflammation [56]. $S$-nitrosylation of surfactant-D protein switches pulmonary surfactant protein-D from antioxidant to a proinflammatory mediator [87].

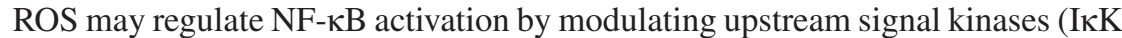
complex) through oxidative modification of signal transducers and/or its binding partners [88]. In early phases of oxidative stress, ROS may enhance NF- $\kappa \mathrm{B}$ activation following exogenous stimuli; however sustained oxidative stress may repress $\mathrm{NF}-\kappa \mathrm{B}$ activation [88]. I $\kappa \mathrm{K}$ complex, mainly I $\kappa \mathrm{K} \beta$, is highly susceptible for redox modification. Exposures to $\mathrm{H}_{2} \mathrm{O}_{2}$ induced oxidative inactivation of I $\mathrm{K} \beta$, which pre-


vation [89]. In another study, $\mathrm{H}_{2} \mathrm{O}_{2}$ posttreatment augmented $\mathrm{I} \kappa \mathrm{K}$ kinase activity in response to TNF $\alpha$ and leads to higher $\mathrm{NF}-\mathrm{\kappa B}$ activation [90]. $\mathrm{H}_{2} \mathrm{O}_{2}$ treatment was also shown to enhance NF- $\mathrm{KB}$ activation in response to IL-1 cytokine by increasing NF-kappa B-inducing kinase activity [91]. I $\mathrm{KK} \beta$ is also susceptible for S-nitrosylation, which inactivates $\mathrm{I} \kappa \mathrm{K} \beta$ resulting in inhibition of $\mathrm{NF}-\kappa \mathrm{B}$ activation [92]. ROS and RNS are shown to directly modify NF- $\kappa \mathrm{B}$ or its associated proteins and alter its transcriptional activity. ROS-dependent phosphorylation of serine-276 on REL-A enhanced transcriptional activity of NF- $\mathrm{KB}$ [93]. S-nitrosylation of p65 subunit inhibited NF- $\mathrm{B}$ activity. Kelleher et al. [94] demonstrated that p65 subunit is S-nitrosylated in unstimulated lung cells and LPS challenge stimulates denitrosylation of $\mathrm{p} 65$ resulting in activation of NF- $\mathrm{KB}$. Excess ROS may also inactivate proteasome, which impedes $\mathrm{IkB}$ degradation and thus inhibits $\mathrm{NF}-\kappa \mathrm{B}$ activation [95]. Certain cellular redox proteins play an important role in modulating upstream pathways leading to NF- $\mathrm{KB}$ activation. In the nucleus, thioredoxin binds and protects oxidation of p65 subunit and enhances its DNA-binding activity. It is also shown that thioredoxin mediates denitrosylation of p65 following LPS exposure and facilitates NF- $\mathrm{\kappa B}$ activation [94] in the lungs of mice. Pretreatment with antioxidants such as N-acetylcysteine [96], GSH [97, 98] or increased expression of 
antioxidant [72, 97, 98] attenuated lipopolysaccharide (LPS)-promoted NF-кB activation emphasizing the role of oxidative stress in regulating NF- $\mathrm{KB}$ activity.

Inflammasome is an intracellular multiprotein complex assembled in the cytoplasm, which recognizes microbial or environmental toxins and DAMPs (e.g. ATP) and activates inflammatory responses. Several airborne environmental pollutants such as silica, ozone, particulate matter and tobacco smoke are shown to activate inflammasome, and therefore, inflammasome signalling is implicated in the pathogenesis of several lung disorders such as acute lung injury, pulmonary fibrosis, COPD and asthma $[99,100]$. Activation of inflammasome produces active caspase1 via autoproteolytic cleavage, which then mediates proteolytic cleavage of precursor pro-IL1 $\beta$ and pro-IL18 into biologically active cytokines. Among the inflammasome members, NLRP3 is redox sensitive, and therefore, intracellular ROS generated by NADPH oxidase or mitochondria have been shown to alter the activation of NLRP3 inflammasome [101]. Ablation of NADPH oxidase or depletion of mitochondrial ROS inhibited ATP-induced caspase-1 activation and IL- $1 \beta$ secretion in macrophages $[102,103]$. ROS may also alter NLRP3 inflammasome activation by oxidizing redox-sensitive binding partners such as thioredoxin interaction protein (TXNIP) and mitochondrial antiviral sensing (MAVS) protein to NLRP3. TXNIP is a negative regulator of thioredoxin. It is shown that ROS generated in response to a wide range of environmental stimuli oxidizes thioredoxin that liberates TXNIP. The liberated TXNIP interacts with NLRP3 and promotes NLRP3 activation [104]. MAVS regulates type 1 interferon and NF-kB signalling following virus infection. It has been shown that ROS may induce MAVS aggregation [105] on the outer membrane of mitochondria, which enables interaction with NLRP3 and promotes activation.

MAPK kinases, namely, ERK1/2, JNK and p38 MAPK, represent key effectors of signal transduction to activate inflammatory responses in the lungs following exposure to environmental toxicants [106]. In macrophages and bronchial epithelial cells, LPS stimulation induces phosphorylation of p38 MAPK and mediates the generation of numerous proinflammatory cytokines such as TNF $\alpha$, IL-6, IL-1 $\beta$ [107] and also T cell (Th1 and Th17)-polarizing cytokines such as IFN $\gamma$, IL-12 and IL-23 [108]. In cigarette smoke-exposed mouse models, specific activation of p38 MAPK is shown to be a determinant of susceptibility to emphysema [106]. Several investigations suggest that ROS plays a pivotal function in activating and/or perpetuating MAPK kinase signalling. Exposure of cells to $\mathrm{H}_{2} \mathrm{O}_{2}$ induces phosphorylation of p38, ERK and JNK [109]. Although precisely how ROS activates MAPK kinase is less understood, it is postulated that ROS mediates oxidative inactivation of protein tyrosine phosphatases and MAPK phosphatases, which inactivate MAPK kinase by dephosphorylating [109, 110]. Because MAPK kinase plays a pivotal role in regulating inflammation, kinase inhibitors, particularly p38 MAPK inhibitors, are shown to be promising drug for treatment of airway disorders such as COPD and asthma [111]. 


\subsubsection{Oxidative Stress in Programmed Cell Death}

Apoptosis (a programmed cell death) is involved in removing damaged, infected and potentially neoplastic cells, and increased apoptotic cell death is involved in the pathogenesis of several lung disorders. Apoptosis can be activated by several factors including receptor-mediated signals and DNA damage; however, in most cases, ROS functions as an upstream activator of apoptosis. Apoptosis is mediated by extrinsic and intrinsic pathways $[40,112,113]$. The extrinsic pathway is mediated through interaction of death ligands of the tumour necrosis factor (TNF) family (FasL/FasR and TNFüFC;/TNFR1) with their appropriate cell surface death receptors, while non-receptor-mediated stimuli are involved in intrinsic signalling pathways that initiate apoptosis. Oxidative stress may induce these processes by activating several signalling pathways, including MAPK (ERK, JNK and p38), cellcycle regulators, protein kinase B and caspases [114]. For instance, 4HNE is reported to enhance the mRNA and protein expression of pro-apoptotic regulators/ adaptors such as BAX and caspases [59, 115]. Further, 4HNE can directly interact with death ligand (Fas) on the cell membrane and activate apoptotic process [114]. Finally, 4HNE alters cytosolic calcium homoeostasis and mitochondrial calcium uptake, resulting in apoptosis [116]. Similarly, cigarette smoke exposure is shown to activate apoptosis via ROS by activating MAPK/STAT1 pathway [117]. Several studies have reported oxidative stress-dependent apoptosis in pulmonary fibrosis, obstructive airway diseases and ARDS [12, 40, 41, 44, 113, 118].

\subsubsection{Oxidative Stress in Mitochondrial Dysfunction}

Besides the 'powerhouse' (ATP production by oxidative phosphorylation) of the cell, mitochondria physically interact and communicate with other organelles to maintain the metabolic homeostasis and many synthetic processes for normal function and survival of cell [13]. Mitochondria may also sense external stressors and alter its function to mount a protective adaptive stress response program [119]. However, prolonged exposures to environmental toxicants induce mitochondrial dysfunction mainly via oxidative stress mechanisms [120]. Mitochondrial dysfunction may present in the form of increased mitochondrial ROS, diminished oxidative phosphorylation, increased mitochondrial mass, secretion of mitochondrial DAMPs, mitochondrial DNA damage, decreased mitochondrial biogenesis and increased accumulation of defective mitochondria $[13,119,121]$. Several studies suggest that mitochondrial dysfunction is a predominant pathological feature in all lung diseases $[13,120,121]$.

In lungs, owing to their dynamic function, alveolar type II epithelial cells, bronchial ciliated epithelial cells, vascular smooth muscle cells and macrophages are richer in mitochondria than other lung cell types. In normal conditions, lung cells preferentially use glucose end product, pyruvate, for oxidative phosphorylation. However, during stressful physiological or pathological conditions (such as increased surfactant production), alveolar type II epithelial cells rely on fatty acids 
for energy demand. Under chronic stress conditions, mitochondrial bioenergetic metabolic function may get altered in lung cells. For example, cigarette smoke exposure is shown to damage mitochondrial structure and affect oxidative phosphorylation in lung cells [122]. Likewise, primary bronchial epithelial cells from severe COPD patients showed accumulation of abnormal mitochondria [122]. Airway smooth muscles and diaphragmatic and external intercoastal muscle of patients with COPD are associated with altered mitochondrial oxidative phosphorylation [123]. Bronchial epithelium in asthmatics is associated with reduced mitochondrial oxidative phosphorylation and decreased expression and activity of cytochrome $c$ oxidase $[120,124,125]$. To meet the energy demand and mount stress response, chronic stress may also induce mitochondrial biogenesis in lung cells. Alveolar type II epithelial cells showed increased mitochondrial biogenesis during acute lung injury, pneumonia and hyperoxia-induced lung injury [126]. Bronchial smooth muscles of asthmatic airways are associated with increased mitochondrial biogenesis, and this was linked to higher expression of nuclear respiratory factor 1 , peroxisome proliferator-activated receptor $\gamma$ coactivator (PGC)-1 $\alpha$ and mitochondrial transcription factor A [127]. Abnormal or defective mitochondria in the cells are constantly removed by a process called mitophagy, which is regulated by PTENinduced kinase 1 (PINK1). Expression of PINK1 is negligible in healthy mitochondria; however its levels increase on the outer mitochondrial membrane of defective mitochondria, which recruits parkin and autophagy proteins and facilitates mitophagy. Impaired mitophagy leads to accumulation of damaged mitochondria in the cells, which promotes cellular senescence [128, 129]. Increased cellular senescence has been observed in the lungs of COPD and IPF patients [128-130]. Exposures to cigarette smoke in lung cells are shown to inhibit mitophagy, increase accumulation of damaged mitochondria $[128,129,131]$ and induce cellular senescence. Alveolar type II cells of IPF patients are associated with abnormal mitochondria due to diminished PINK1 expression [132]. In mouse models, PINK1 knockdown impaired mitophagy and increased accumulation of defective mitochondria and promoted fibrosis in aging lungs [132]. On contrary, increased mitophagy may also contribute to pathogenesis of lung diseases. For example, Staphylococcus aureus infection increased mitochondrial expression of PINK1 and mediated acute lung injury, which was ablated in PINK1 knockout mice [133]. Mitochondrial dysfunction may also lead to leakage of cytochrome c, which triggers programmed cell death [116, 134]. Mitochondria have been shown to regulate various forms of cell death such as extrinsic apoptosis, intrinsic apoptosis, necroptosis and pyroptosis [134], and all these forms of cell death have been reported in various lung diseases including COPD, asthma and IPF.

At physiological concentrations, many mitochondrial-derived molecules including ROS help in normal cellular signalling. However, when secreted in excess, mitochondrial-derived molecules act as mitochondrial DAMPs (mtDAMPs) and contribute to lung injury. Mitochondrial DNA (mtDNA), a well-studied mtDAMP, is released by damaged mitochondria, which is shown to engage TLR9 and inflammasome to initiate inflammatory responses in lung cells [135, 136]. Circulatory levels of mtDNA correlate well with severity and mortality in sepsis and ARDS 
patients [137]. Excess ATP released in the lungs by dead or damaged cells also acts as mtDAMPs and activates inflammatory response via NLRP3 inflammasome [119, 138]. Elevated levels of ATP are reported in bronchoalveolar lavage fluid of patients with COPD [139] and asthma as well as in mouse models of asthma [140] and pulmonary fibrosis [141]. Other mtDAMPs such as TFAM and $\mathrm{N}$-formyl peptide are also implicated in driving inflammatory responses in lungs [119]. Cardiolipin, a predominant lipid located in mitochondrial inner membrane, is released by damaged mitochondria and acts as mtDAMP. Levels of cardiolipin increase during lung injury and are shown to mediate cell death and activate inflammasome signals [133, 142]. Additionally, cardiolipin in lung fluid was shown to inhibit surfactant activity and worsen lung function in mouse models of pneumonia [143]. Finally, mitochondrial-derived ROS plays diverse roles in the pathogenesis of lung diseases including perpetuating oxidative stress, augmenting TLR-NF- $\mathrm{KB}$ signalling and cell death $[13,81,119,125,134,135,144]$.

\subsubsection{Oxidative Stress in Promoting Endoplasmic Reticulum Stress}

The endoplasmic reticulum (ER) is involved in protein biosynthesis and posttranslational modifications and perturbation of ER homeostasis results in ER stress which affects both these process. To overcome the ER stress, cells initiate an evolutionarily conserved mechanism called unfolded protein response (UPR). Activation of UPR leads to decrease in protein synthesis by selectively inhibiting translation, increases protein folding machinery and removes misfolded proteins through endoplasmic reticulum-associated degradation (ERAD) pathway [145]. If UPR fails to alleviate ER stress, it activates apoptotic signalling mechanism [146] and, thus, helps in removal of damaged or stressed cells. Chronic ER stress is pathological and is associated in the pathogenesis of many lung disorders. Markers of ER stress are elevated in neutrophil-associated steroid-resistant asthma [147]. In COPD model, cigarette smoke exposure elicited ER stress and apoptosis [148, 149]. ER stress was found to be elevated in lungs of human IPF and murine models of pulmonary fibrosis [146]. ER stress is also reported to be involved in the hyperoxia-induced acute lung injury in neonates [150]. Sustained oxidative stress milieu may promote ER stress by increasing cellular stress and decreasing the efficiency of protein folding pathways [151]. A relationship has been established between ROS generation and activation of ER stress response [152]. NADPH oxidase(s) and mitochondria are reported as a probable ROS source during ER stress.

\subsubsection{Oxidative Stress in Epigenetic Alterations}

Chronic oxidative stress state may disturb the epigenetic state of the cell by multiple mechanisms. For example, superoxide radicals can directly mediate transfer of a methyl group from SAM to a cytosine residue without the need of DNMT by 
deprotonating C5 [153]. ROS may increase DNMT expression and indirectly affect DNA methylation [154]. ROS may also directly or indirectly modify acetylation of histones by modifying activity or the expression of histone methyltransferases (HMTs) and/or histone acetyltransferases (HATs) [155]. On the other side, ROS and RNS are reported to modulate the activity of HDACs (histone deacetylase) that may influence the expression of target genes by removing acetyl groups [156-159] on histones. Recently, various ncRNAs, in particular microRNAs (miRNAs), are regulated by ROS. Interestingly, some miRNAs such as miR-9, miR-21, miR-200 and miR-210 are shown to control cellular ROS levels and are termed as redoximiRs [160]. ROS are also shown to interfere with miRNA biogenesis process as well as miRNA maturation by modulating Dicer and argonaute RISC catalytic component [161]. In the context of the lung, several lines of evidence support that ROSdependent changes in the epigenetic background play an important role in the pathogenesis of respiratory diseases. For instance, cigarette smoke exposures inhibit HDAC2 enzyme activity through oxidative and nitrosative modification, which leads to enhanced inflammatory responses, senescence and steroid resistance in COPD $[158,159]$. Another study shows that Sirtuin 1 promotes lung epithelial cell death following hyperoxia by selectively deacetylating the transcription factor nuclear factor (erythroid-derived 2)-like 2 (NRF2), accompanied by reduced levels of antioxidant enzymes [162]. In case of asthma, one study reported that exposure to environmental particulate matter could lead to demethylation of iNOS gene; subsequently this may lead to increased expression of proinflammatory iNOS, leading to lung inflammation [163]. The involvement of many factors including ROS in epigenetics of IPF has been reviewed [164].

\subsubsection{Oxidative Stress in Profibrotic Mechanisms}

Fibrotic lungs are associated with increased oxidative stress, as indicated by the elevated levels of biomarkers of lipid, protein and DNA damage, and several reports have implicated ROS in profibrotic processes. Activation and proliferation of fibroblasts/myofibroblasts are thought to be responsible for the excessive synthesis and accumulation of extracellular matrix (ECM) proteins, resulting in fibrosis. During the inflammatory phase of fibrosis, ROS along with growth factors (TGF- $\beta$, PDGF and CTGF) and cytokines (IL-6 and IL-13) stimulate fibroblast to produce ECM. Among these, TGF- $\beta$ is the most dynamic pro-fibrogenic cytokine, which regulates important biological processes such as EMT, fibroblast activation and differentiation and ECM production [165]. ROS may influence the transformation of latent TGF- $\beta$ complex into its active form, which then binds to its receptors and activates signalling pathways such as SMAD-dependent or SMAD-independent (e.g. MAPK and PI3K) pathways and enhances the transcriptional activity of various profibrotic genes such as $\alpha$-SMA and COL1 [166]. On the other hand, elevated TGF- $\beta$ itself reciprocally induces the production of NOX4-dependent ROS [167]. NOX4 is selectively upregulated in the lungs of IPF patients and is associated with the endothelial cell dysfunction and hypoxia [14, 55]. Elevated NOX4-generated 
ROS triggers DNA oxidation and activates other ROS-dependent signalling pathways such as JNK and NF-кB [168]. Silencing of NOX4 by siRNA inhibited TGF$\beta$-mediated profibrotic responses in the lungs of mice [55]. Further, NOX4 knockout mice and use of NOX4 inhibitor in mice protected against bleomycin-induced acute lung injury and the onset of fibrosis [76, 169]. In fibroblasts, mitochondrial ROS has been shown to induce the expression of profibrotic genes during fibroblast differentiation [144]. ROS may also modulate integrins, transmembrane receptors that activate FAK, which in turn activate rac1 protein and initiate production of collagen and other profibrotic actors (CTGF and $\alpha$-SMA) [170]. ROS and RNS may modulate activity of matrix metalloproteinases (MMPs) through the inhibition of cysteine switch and thus influence ECM degradation. ROS are also shown to induce epithelial cell senescence that may result in a diminished capacity for regeneration of epithelium [171]. In IPF, epithelial damage and epithelial cell senescence in the lung are interconnected with increased mitochondrial ROS production. Similarly, in IPF fibroblasts, ROS generation is reported to require for the maintenance and differentiation [172]. Furthermore, oxidative stress may cause ER stress, which facilitates fibrogenesis through activation of EMT, pro-apoptotic pathways and inflammatory responses [146]. In summary, oxidative stress can alter different cellular processes that amplify fibrotic responses.

\subsubsection{Oxidative Stress in Airway Mucus Hypersecretion}

A thin layer of gelatinous mucus covers the apical epithelial surfaces of mammalian respiratory tract, which forms a protective barrier against airborne microbes and toxins, but conversely, excessive mucus production becomes pathologic in mucoobstructive airway diseases [173]. Mucus is secreted by goblet cells in the airway epithelium and is mainly composed of mucin, which is a large filamentous glycoprotein [174]. Mucus is also rich in antioxidant scavengers such as glutathione, uric acid and ascorbic acid. Chronic airway inflammatory diseases such as chronic bronchitis and asthma are characterized by mucus hypersecretion [175], and ROS (hydroxyl radicals, superoxide anions and hydrogen peroxides) are key regulators of mucus production in goblet cells via transcriptional regulation of mucin genes [176]. Of 12 mucin genes, MUC5AC is a major inducible mucin gene in airways and reported to be highly expressed in muco-obstructive airway disorders [177, 178]. Increased intracellular ROS and exposure to hydrogen peroxide stimulate EGFR tyrosine phosphorylation and subsequent activation of ERK1/2, resulting in increased expression of MUC5AC in lung epithelial cells [176, 179]. Similarly in nasal epithelium, exogenous hydrogen peroxides exposure induces MUC5AC expression through activation of EGFR-ERK1/2 signalling [178]. Yu et al. [180] reported that ROS depolymerizes hyaluronan into fragments and these hyaluronan fragments interact with CD44 receptor to activate tissue kallikrein, which cleaves precursors of EGF into mature EGF. Subsequently, mature EGF binds and activates EGFR leading to activation of ERK1/2. In addition, ROS is reported to contribute to goblet cell metaplasia, a major player in mucin overproduction through JAK/STAT 
pathway [181]. Likewise, activation of other pathways, such as NF- $\kappa B$, is also linked to ROS-mediated MUC5AC production in airways. However, the majority of the studies suggest that EGFR is involved in ROS-mediated mucus hypersecretion $[173,177,178]$.

\subsection{Antioxidant Responses in Lungs}

The lungs are exceptionally exposed to greater oxidative environment than other organs. The inhaled toxicants are by themselves oxidants or may induce oxidative stress inside lung cells. To protect from the inhaled environmental oxidants, lungs are endowed with efficient antioxidant defences that includes both non-enzymatic and enzymatic antioxidant defences.

\subsubsection{Antioxidant System in Respiratory Tract Lining Fluid}

The airways are covered with respiratory tract epithelial lining fluid (RTLF) which forms a physical barrier between the external environment and underlying respiratory tract epithelial cell layer. The respiratory tract lining fluid traps most of the inhaled toxicants, and by the help of mucociliary action, these trapped toxicants are cleared from the lungs. The respiratory tract lining fluid is rich in many nonenzymatic low-molecular-weight antioxidant scavengers, which directly interact and detoxify the inhaled oxidants and thereby prevent the direct contact of inhaled toxicants with the underlying epithelium. The major antioxidant molecules in the RTLF are GSH, ascorbic acid, uric acid and vitamin E (Fig. 5.1). Additionally, airway epithelial cells secrete certain antioxidant proteins into RTLF, which also function as antioxidant scavengers.

\subsubsection{Glutathione (GSH)}

Glutathione, a thiol-tripeptide comprised of glutamate, cysteine and glycine, is the most important antioxidant in RTLF, and its levels in RTLF are close to 100 times more than in the plasma [182]. GSH scavenges a number of ROS products including hydroxyl, $\mathrm{H}_{2} \mathrm{O}_{2}$, hypochlorous acid and lipid peroxyl radical generated during exposures to inhaled oxidants such as cigarette smoke, ozone and allergens, and therefore, reduced bronchoalveolar lavage GSH levels has been a hallmark feature of many pulmonary diseases including COPD, asthma, ARDS and IPF [183]. Besides scavenging ROS, GSH is a co-substrate for the enzyme glutathione peroxidase and glutathione S-transferase which mediate detoxification of lipid hydroperoxides and xenobiotics, respectively. GSH in RTLF also protects secretory antiproteases such as alpha-1-antitrypsin, alpha-2-macroglobulin and secretory leukoprotease inhibitor from oxidative inactivation [184]. Therefore, a lower level of tissue GSH intensifies oxidant-induced lung inflammatory injury. GSH also maintains thiol status of extraand intracellular proteins and facilitates post-translational modification of proteins such as S-glutathionylation. Protein S-glutathionylation may alter the function of 
many intracellular proteins. For example, S-glutathionylation inhibits DNA-binding activity of p65 or p50 subunits [185], and S-glutathionylation inactivates IкK $\beta$ [186] resulting in diminished NF- $\kappa \mathrm{B}$ activity.

\subsubsection{Ascorbic Acid}

Ascorbic acid is another major antioxidant in RTLF. It directly reduces the oxidative potential of oxidants present in tobacco smoke [187] or particulate matter [188] as well as inhibits ROS generation by NADPH oxidase activity [189]. Besides reducing the inhaled oxidants, ascorbic acid also reduces oxidized antioxidants in RTLF such as vitamin E, thereby maintaining the total antioxidant capacity of the lungs during oxidative insult. Ascorbic acid is rapidly used in RTLF fluid upon exposures to environmental oxidants including ozone, nitrogen dioxide, particulate matter and tobacco smoke [190-192] as indicated by the depletion of ascorbic acid levels. Supplementation of ascorbic acid protected from cigarette smoke-induced emphysema by inhibiting protein oxidation in mouse models [192] highlighting the antioxidant potential of ascorbic acid in the lungs. Asthmatics are associated with lower levels of ascorbic acid [193, 194], and the beneficial effect of supplementation of ascorbic acid in asthmatics has been mixed and inconclusive [195]. Ascorbic acid has been shown to attenuate acute lung injury caused by inhalation of oxidant chlorine gas [196]. Ascorbic acid may also take part in pro-oxidant activity in the presence of free iron by taking part in Fenton reaction.

\subsubsection{Uric Acid}

Uric acid formed due to purine metabolism is one of the major water-soluble scavengers of singlet oxygen, ozone and peroxylnitrite (ONOO) in RTLF [190] . Uric acid has been shown to be a major antioxidant in nasal secretion [197] and RTLF and helps in the removal of inhaled ozone and neutralizes the oxidative potential of inhaled particulate matter in humans [198]. Uric acid also reacts and neutralizes gaseous free radical nitrogen dioxide [190, 199]. The antioxidant scavenging activity of uric acid greatly depends on ascorbic acid and hydrophilic environment. Uric acid reacts with radical species and forms urate free radical which is then quenched by ascorbic acid. In lipophilic environment, uric acid fails to stop the self-propagating lipid peroxidation reaction. Subnormal levels of serum uric acid were associated with greater risk for COPD and greater morbidity, including reduced 6-minute walk test and greater burden of exacerbations [200, 201].

\subsubsection{Vitamin E}

Vitamin E (tocopherol) is a lipophilic antioxidant scavenger in RTLF which neutralizes ROS and attenuates self-propagating lipid peroxidation reactions in the airways. Patients with asthma and COPD are associated with lower serum levels of vitamin E [193] as compared to healthy subjects, and this formed the basis for vitamin E supplementation trials to prevent respiratory diseases. Vitamin E trials reduced levels of markers of oxidative damage in smokers [202]. Dietary intake of vitamin E improved lung function in healthy aging population [203]. Vitamin E supplements reduced endotoxin-induced sputum eosinophilia in asthma patients 
[204]. In experimental mouse models, administration of vitamin E isoform $\gamma$-tocotrienol protected from cigarette smoke-induced emphysema [205] and dust mite-induced asthma. However, supplementation of vitamin E showed no benefits in the management or treatment of asthmatics [206].

\subsubsection{Lung-Specific Secretory Proteins in RTLF as Antioxidants}

Pulmonary surfactant which lines the alveoli surface is composed of a mixture of $90 \%$ phospholipids and $10 \%$ surfactant proteins. The surfactant proteins included high-molecular-weight hydrophilic surfactant proteins A and D and low-molecularweight hydrophobic surfactant proteins B and C. Unsaturated phospholipids and surfactant protein are prone for oxidative inactivation following exposures to environmental oxidants such as ozone. Both surfactant proteins A and D exhibited direct antioxidant activity and protected phospholipids and LDL from copper or ferric chloride-induced oxidation [207]. Surfactant proteins A and D also protected macrophages from hydroperoxide-induced cell death [207]. Clara cell-16 (CC16) protein secreted by clara cells also exhibits antioxidant and anti-inflammatory activity [208]. Mice with genetic disruption of CC16 showed elevated oxidative damage and structural injury following exposure to cigarette smoke [209]. Low circulating levels of CC16 are shown to be associated with poor lung function growth in children [210] and smoking-dependent lung function decline in adults [211] as well as patients with COPD and asthma [208].

\subsubsection{Enzymatic Antioxidant System in Lungs}

Lungs are endowed with robust antioxidant protein defences to minimize oxidative stress caused by airborne environmental toxicants. Major pulmonary antioxidant enzymes include superoxide dismutase, catalase, glutathione peroxidase, glutathione reductase, hemeoxygenase-1, peroxiredoxin-1, thioredoxin and thioredoxin reductase [40, 41, 212, 213]. Exposures to environmental oxidants such as cigarette smoke lead to the coordinated activation of all these antioxidant proteins [39-41] (as illustrated in Fig. 5.1) and help in efficient detoxification of ROS and lipid peroxides generated in the lungs. The importance of individual antioxidant enzyme has been exemplified using knockout and transgenic mouse models.

All the three isoforms of superoxide dismutase, extracellular-SOD (EC-SOD), copper/zinc-SOD ( $\mathrm{Cu} / \mathrm{Zn}$-SOD) and manganese-SOD (Mn-SOD), are present in lungs and provide first line of defence against superoxide radicals. The importance of each of the SOD isoforms in protecting lungs from oxidants has been well studied. EC-SOD prevented fibrosis in lungs by inhibiting oxidative degradation of the matrix proteins, type I and type IV collagen [214]. Cigarette smoke exposure and elastase instillation caused greater emphysema in EC-SOD-deficient mice; however transgenic EC-SOD mice were protected from emphysema [215]. Similarly, overexpression of human $\mathrm{Cu} / \mathrm{Zn}-\mathrm{SOD}$ in lungs protected from cigarette smoke-induced 


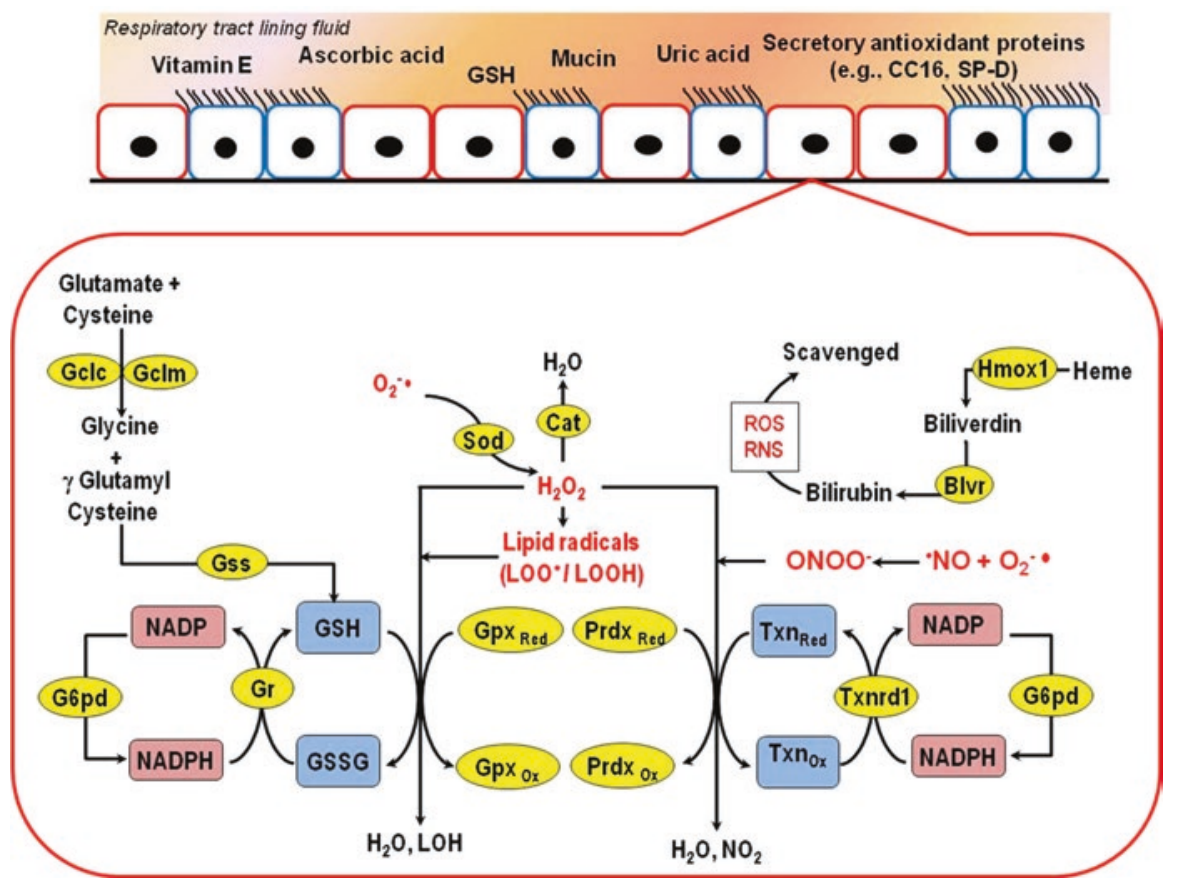

Fig. 5.1 Antioxidant defenses in lungs

emphysema in mouse model [216]. Overexpression of Mn-SOD has also been reported in alveolar macrophages during sarcoidosis and in the lung tissue of IPF patients [213]. SOD is highly sensitive for oxidative inactivation, and therefore, SOD levels are depleted in disease lungs. In IPF, there was no expression of EC-SOD in fibrotic areas where there is an enhancement of oxidative burst [214]. Enzyme activity of SOD was significantly low in asthmatics as compared to healthy subjects, which is further depleted during asthma attack [217,218]. Oxidative and nitrosative modification of Mn-SOD was observed in the airways of asthmatic, which correlated with asthma severity [217]. Therefore, increasing SOD levels in the lungs by pharmacological approaches including SOD mimetics are thought to be a promising approach for mitigating pathogenesis of pulmonary disorders.

Glutathione peroxidase (GPx) detoxifies hydrogen peroxide and reactive lipid hydroperoxides using GSH as an electron donor. In mammalian lungs, four major selenium-containing GPx isoforms are expressed - GPX1 (classical GPx), GPX2 (gastrointestinal GPx), GPX3 (extracellular GPx) and GPX4 (phospholipid GPx). Bronchial epithelial cells and alveolar macrophages produce Gpx3 in epithelial lining fluid, which detoxify lipid hydroperoxides generated in RTLF. GPx2 is a predominant glutathione peroxidase expressed in the lungs following cigarette smoke exposure and silencing GPx 2 by RNA interference enhanced cytotoxicity in bronchial epithelial cells following treatment with cigarette smoke extract [42]. In comparison with wild type, GPx2-deficient mice showed greater levels of oxidative 
damage, airway inflammation and airway hyperresponsiveness in ovalbumininduced asthma mouse model [219]. Basal levels of GPx in lungs were shown to be a key determinant of severity of pulmonary fibrosis in mouse models [220]. Peroxiredoxins are the family of peroxidase enzymes, which play a dominant role in detoxification of hydrogen peroxide within the cells. Human lung expresses all the six members of a peroxiredoxin family [221]. Thioredoxin reductase is a selenium-containing flavoprotein oxidoreductase enzyme expressed in mammalian lungs, which primarily catalyses NADPH-dependent reduction of thioredoxin, an important redox protein involved in transcriptional regulation of NF- $\mathrm{KB}$ [94]. Heme oxygenase-1 (HO-1) is a highly inducible protein in the lungs which exhibits antiapoptotic, anti-inflammatory and antioxidant activities. HO-1 catalyses heme to carbon monoxide and biliverdin and the latter is converted to bilirubin. Although the mechanism by which HO-1 mediates antioxidant and anti-inflammatory activity is less understood, the end byproducts of HO-1 enzyme activity, $\mathrm{CO}$, bilirubin and $\mathrm{Fe}$ are shown to mediate the beneficial effects [222]. HO-1 knockout mice display greater inflammation, apoptosis and tissue injury following an ischemic reperfusion injury [223], while lung-specific expression mitigated LPS- and hyperoxia-induced lung inflammation [224, 225].

\subsubsection{Regulation of Antioxidant Enzymes in Lungs}

Many lines of evidence show that transcription factor Nrf2 is a central regulator of nearly all cellular antioxidant proteins in the lungs and other organs [226]. In a normal cell, Nrf2 is held in the cytoplasm by a cysteine-rich, redox sensor Keap1 protein, which functions as an adaptor molecule and bridges Nrf2 with Cul3-based E3 ubiquitin ligase [227, 228]. Under normal condition, Keap1-Cul3-based E3 ubiquitin ligase ubiquitinates Nrf2 and directs it to proteasomal degradation. However, upon exposure to ROS and electrophiles, Keap1 protein undergoes conformational change due to oxidative modification of its cysteine residues, which disrupts the interaction of Nrf2 with Cul3-dependent E3 ligase and prevents Nrf2 ubiquitination. Stabilized Nrf2 moves into the nucleus and mediates transcriptional activation of its target genes by binding to cis-element called 'antioxidant response element' in the promoter region. Genetic disruption of Nrf2 ablates transcriptional induction of antioxidant genes in the lungs and sensitizes the mice to several environmental lung diseases such as cigarette smoke-induced emphysema [41], allergen-induced asthma [229], LPS-induced acute lung injury [97] and bleomycin-induced pulmonary fibrosis [230] and sepsis [72, 74, 231]. In contrast, activation of Nrf2 by pharmacological activators and genetic disruption of Keap1 protected mice from development of these pulmonary diseases [226]. Nrf2-regulated antioxidant has been shown to be downregulated in lungs of patients with COPD [232] and IPF [233], underscoring the importance of Nrf2 pathway in protecting the lungs from oxidative stress. Besides Nrf2, NF- $\mathrm{BB}$ and AP-1 also regulate transcriptional expression of certain antioxidant genes in the lungs $[88,234]$. 


\subsubsection{Antioxidant Therapy for Lung Diseases}

Despite the compelling evidence from preclinical and clinical studies that pulmonary antioxidants play a pivotal role in protecting from environmental pulmonary diseases, clinical trials testing antioxidant therapy have shown modest to no significant beneficial effects. Clinical trials with $\mathrm{N}$-acetyl-L-cysteine (NAC) supplementation have shown mixed results. Meta-analysis of all clinical trials using oral NAC concluded that long-term intake of NAC may reduce the acute exacerbations of chronic bronchitis [235]. However, more recent randomized double-blinded multicentre clinical trial of oral NAC reported no beneficial effect in the prevention of lung function decline and COPD exacerbation [236]. Vitamin C and E clinical trials showed no improvement on lung function decline in COPD patients [237]. Supplementation of Nrf2 activator, sulforaphane, in the form of broccoli sprout homogenates reduced bronchoconstrictor hyperresponsiveness in asthmatics [238]. In a randomized clinical trial, supplementation of sulforaphane showed no significant upregulation of Nrf2-regulated antioxidants in lungs of COPD patients [239]. In another study, consumption of broccoli sprout showed no effect on eosinophilic inflammation as well as markers of oxidative stress in atopic asthmatic patients [240]. In smokers, consumption of broccoli sprout homogenates reduced influenza virus-induced inflammation [241]. Consumption of broccoli tea has been reported to promote rapid and sustain detoxification of air pollutants in a randomized clinical trial in China [242]. The reasons for lack of consistent benefits of antioxidant trials for pulmonary disease are still puzzling. Perhaps it could be combination of poor efficacy of a single antioxidant agent as well as limited bioavailability.

\subsection{Conclusions}

Oxidative stress is a central hallmark pathological feature of all the respiratory disease. Oxidative stress elicits both reversible and irreversible macromolecule damage (oxidative modification of lipids, proteins and DNA). As illustrated in Fig. 5.2, besides inducing macromolecular damage, oxidative stress propagates the disease by augmenting other pathological processes such as inflammatory responses, mitochondrial dysfunction, ER stress, profibrotic signalling, cell death and epigenetic changes. Experimental evidences suggest that antioxidant therapy may prevent or mitigate oxidative stress-mediated macromolecular damage and abnormal signal transductions and, thereby, protect from development and progression of disease. However so far, most antioxidant clinical trials have shown poor efficacy to mitigate disease progression, which may be attributed to insufficient bioavailability of antioxidant agent in the lungs and also inability to reverse pathogenic events such as epigenetic changes, macromolecule damage and mitochondrial dysfunction. Antioxidant alone may not be effective in treatment of diseases; however it could be a promising adjunctive therapy. 


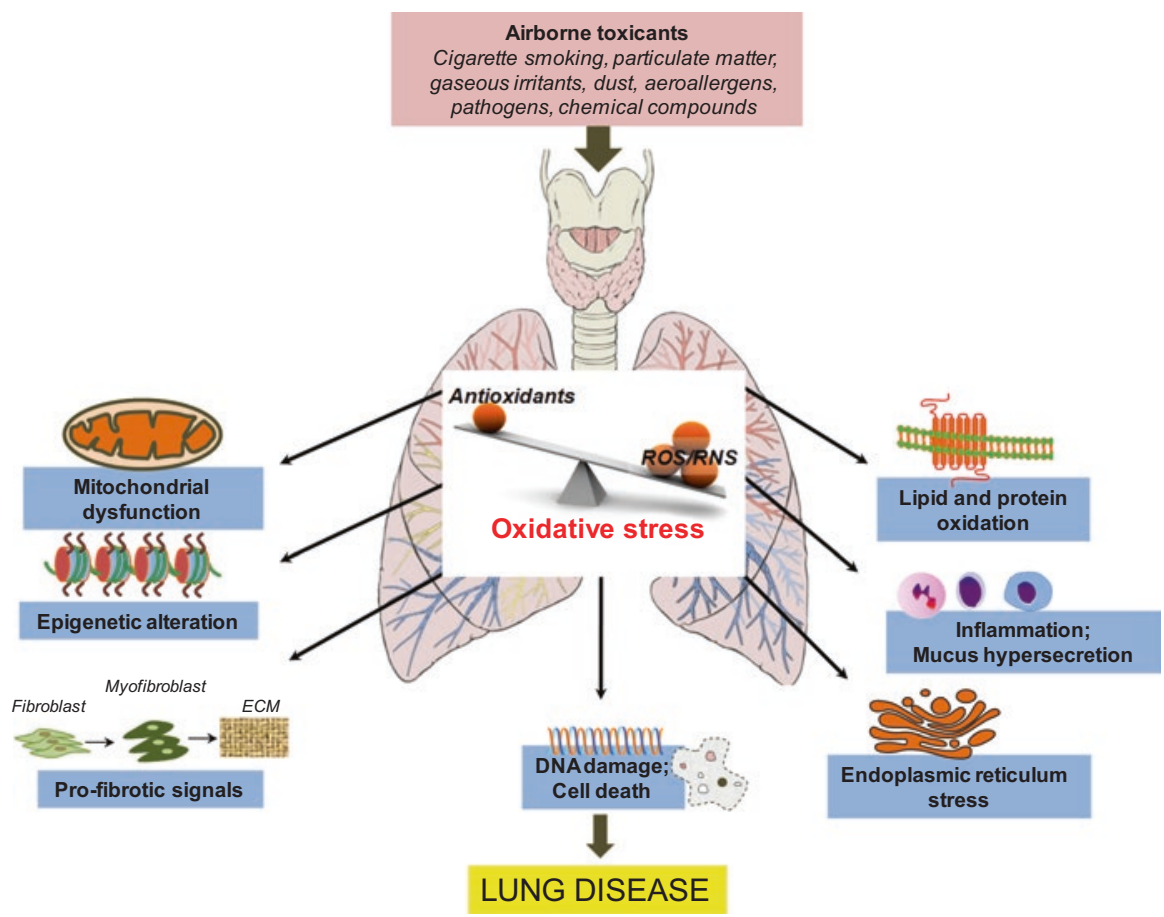

Fig. 5.2 Oxidative stress-mediated pathological events in driving lung diseases

Acknowledgements This work was supported by Ramalingaswami Re-Entry Fellowship grant from the Department of Biotechnology, Ministry of Science and Technology, India to R.K.T and S.R.

\section{References}

1. Collaborators GCoD (2018) Global, regional, and national age-sex-specific mortality for 282 causes of death in 195 countries and territories, 1980-2017: a systematic analysis for the global burden of disease study 2017. Lancet 392(10159):1736-1788

2. Collaborators GDaH (2018) Global, regional, and national disability-adjusted life-years (DALYs) for 359 diseases and injuries and healthy life expectancy (HALE) for 195 countries and territories, 1990-2017: a systematic analysis for the global burden of disease study 2017. Lancet 392(10159):1859-1922

3. Ferkol T, Schraufnagel D (2014) The global burden of respiratory disease. Ann Am Thorac Soc 11(3):404-406

4. Dröge W (2002) Free radicals in the physiological control of cell function. Physiol Rev 82(1):47-95

5. Halliwell B (1994) Free radicals, antioxidants, and human disease: curiosity, cause, or consequence? Lancet 344(8924): 721-724

6. Cantu-Medellin N, Kelley EE (2013) Xanthine oxidoreductase-catalyzed reactive species generation: a process in critical need of reevaluation. Redox Biol 1:353-358 
7. Antosova M, Mokra D, Pepucha L, Plevkova J, Buday T, Sterusky M et al (2017) Physiology of nitric oxide in the respiratory system. Physiol Res 66(Suppl 2):S159-SS72

8. Bernard K, Hecker L, Luckhardt TR, Cheng G, Thannickal VJ (2014) NADPH oxidases in lung health and disease. Antioxid Redox Signal 20(17):2838-2853

9. Al Ghouleh I, Khoo NK, Knaus UG, Griendling KK, Touyz RM, Thannickal VJ et al (2011) Oxidases and peroxidases in cardiovascular and lung disease: new concepts in reactive oxygen species signaling. Free Radic Biol Med 51(7):1271-1288

10. Bedard K, Krause KH (2007) The NOX family of ROS-generating NADPH oxidases: physiology and pathophysiology. Physiol Rev 87(1):245-313

11. Winterbourn CC, Kettle AJ, Hampton MB (2016) Reactive oxygen species and neutrophil function. Annu Rev Biochem 85:765-792

12. Beers MF, Morrisey EE (2011) The three R's of lung health and disease: repair, remodeling, and regeneration. J Clin Invest 121(6):2065-2073

13. Cloonan SM, Choi AM (2016) Mitochondria in lung disease. J Clin Invest 126(3):809-820

14. Thannickal VJ (2012) Mechanisms of pulmonary fibrosis: role of activated myofibroblasts and NADPH oxidase. Fibrogenesis Tissue Repair 5(Suppl 1):S23

15. Kelley EE, Khoo NK, Hundley NJ, Malik UZ, Freeman BA, Tarpey MM (2010) Hydrogen peroxide is the major oxidant product of xanthine oxidase. Free Radic Biol Med 48(4):493-498

16. Hesslinger C, Strub A, Boer R, Ulrich WR, Lehner MD, Braun C (2009) Inhibition of inducible nitric oxide synthase in respiratory diseases. Biochem Soc Trans 37(Pt 4):886-891

17. Sugiura H, Ichinose M (2011) Nitrative stress in inflammatory lung diseases. Nitric Oxide 25(2): 138-144

18. Ghio AJ, Soukup JM, Madden MC (2018) The toxicology of air pollution predicts its epidemiology. Inhal Toxicol:1-8

19. Feld-Cook EE, Bovenkamp-Langlois L, Lomnicki SM (2017) Effect of particulate matter mineral composition on environmentally persistent free radical (EPFR) formation. Environ Sci Technol 51(18):10396-10402

20. Pryor WA (1992) Biological effects of cigarette smoke, wood smoke, and the smoke from plastics: the use of electron spin resonance. Free Radic Biol Med 13(6):659-676

21. Nel A (2005) Atmosphere. Air pollution-related illness: effects of particles. Science 308(5723):804-806

22. Hogg JC, Hackett TL (2018) Structure and function relationships in diseases of the small airways. Ann Am Thorac Soc 15(Supplement_1):S18-S25

23. Pinkerton KE, Green FH, Saiki C, Vallyathan V, Plopper CG, Gopal V et al (2000) Distribution of particulate matter and tissue remodeling in the human lung. Environ Health Perspect 108(11):1063-1069

24. Rostami AA (2009) Computational modeling of aerosol deposition in respiratory tract: a review. Inhal Toxicol 21(4):262-290

25. Roper C, Chubb LG, Cambal L, Tunno B, Clougherty JE, Mischler SE (2015) Characterization of ambient and extracted PM2.5 collected on filters for toxicology applications. Inhal Toxicol 27(13):673-681

26. Church DF, Pryor WA (1985) Free-radical chemistry of cigarette smoke and its toxicological implications. Environ Health Perspect 64:111-126

27. Song Y, Buettner GR (2010) Thermodynamic and kinetic considerations for the reaction of semiquinone radicals to form superoxide and hydrogen peroxide. Free Radic Biol Med 49(6):919-962

28. Pryor WA, Prier DG, Church DF (1983) Electron-spin resonance study of mainstream and sidestream cigarette smoke: nature of the free radicals in gas-phase smoke and in cigarette tar. Environ Health Perspect 47:345-355

29. Michaudel C, Fauconnier L, Julé Y, Ryffel B (2018) Functional and morphological differences of the lung upon acute and chronic ozone exposure in mice. Sci Rep 8(1):10611

30. Hogg JC, Timens W (2009) The pathology of chronic obstructive pulmonary disease. Annu Rev Pathol 4:435-459 
31. Hogg JC, Pare PD, Hackett TL (2017) The contribution of small airway obstruction to the pathogenesis of chronic obstructive pulmonary disease. Physiol Rev 97(2):529-552

32. Hecker L (2018) Mechanisms and consequences of oxidative stress in lung disease: therapeutic implications for an aging populace. Am J Physiol Lung Cell Mol Physiol 314(4):L642-LL53

33. Young RP, Hopkins R, Black PN, Eddy C, Wu L, Gamble GD et al (2006) Functional variants of antioxidant genes in smokers with COPD and in those with normal lung function. Thorax 61(5):394-399

34. Celedón JC, Lange C, Raby BA, Litonjua AA, Palmer LJ, DeMeo DL et al (2004) The transforming growth factor-betal (TGFB1) gene is associated with chronic obstructive pulmonary disease (COPD). Hum Mol Genet 13(15):1649-1656

35. Küçükaycan M, Van Krugten M, Pennings HJ, Huizinga TW, Buurman WA, Dentener MA et al (2002) Tumor necrosis factor-alpha $+489 \mathrm{G} / \mathrm{a}$ gene polymorphism is associated with chronic obstructive pulmonary disease. Respir Res 3:29

36. Keatings VM, Cave SJ, Henry MJ, Morgan K, O'Connor CM, FitzGerald MX et al (2000) A polymorphism in the tumor necrosis factor-alpha gene promoter region may predispose to a poor prognosis in COPD. Chest 118(4):971-975

37. Sandford AJ, Paré PD (2000) Genetic risk factors for chronic obstructive pulmonary disease. Clin Chest Med 21(4):633-643

38. Barnes PJ, Burney PG, Silverman EK, Celli BR, Vestbo J, Wedzicha JA et al (2015) Chronic obstructive pulmonary disease. Nat Rev Dis Primers 1:15076

39. Tuder RM, Petrache I (2012) Pathogenesis of chronic obstructive pulmonary disease. J Clin Invest 122(8):2749-2755

40. Yoshida T, Tuder RM (2007) Pathobiology of cigarette smoke-induced chronic obstructive pulmonary disease. Physiol Rev 87(3):1047-1082

41. Rangasamy T, Cho CY, Thimmulappa RK, Zhen L, Srisuma SS, Kensler TW et al (2004) Genetic ablation of Nrf2 enhances susceptibility to cigarette smoke-induced emphysema in mice. J Clin Invest 114(9):1248-1259

42. Singh A, Rangasamy T, Thimmulappa RK, Lee H, Osburn WO, Brigelius-Flohé R et al (2006) Glutathione peroxidase 2, the major cigarette smoke-inducible isoform of GPX in lungs, is regulated by Nrf2. Am J Respir Cell Mol Biol 35(6):639-650

43. Thimmulappa RK, Gang X, Kim JH, Sussan TE, Witztum JL, Biswal S (2012) Oxidized phospholipids impair pulmonary antibacterial defenses: evidence in mice exposed to cigarette smoke. Biochem Biophys Res Commun 426(2):253-259

44. Yoshida T, Mett I, Bhunia AK, Bowman J, Perez M, Zhang L et al (2010) Rtp801, a suppressor of mTOR signaling, is an essential mediator of cigarette smoke-induced pulmonary injury and emphysema. Nat Med 16(7):767-773

45. Kirkham PA, Barnes PJ (2013) Oxidative stress in COPD. Chest 144(1):266-273

46. Russell RJ, Brightling C (2017) Pathogenesis of asthma: implications for precision medicine. Clin Sci (Lond) 131(14):1723-1735

47. Barnes PJ (2018) Targeting cytokines to treat asthma and chronic obstructive pulmonary disease. Nat Rev Immunol 18(7):454-466

48. Comhair SA, Erzurum SC (2010) Redox control of asthma: molecular mechanisms and therapeutic opportunities. Antioxid Redox Signal 12(1):93-124

49. Ware LB, Matthay MA (2000) The acute respiratory distress syndrome. N Engl J Med 342(18):1334-1349

50. Rajasekaran S, Pattarayan D, Rajaguru P, Sudhakar Gandhi PS, Thimmulappa RK (2016) MicroRNA regulation of acute lung injury and acute respiratory distress syndrome. J Cell Physiol 231(10):2097-2106

51. Tsushima K, King LS, Aggarwal NR, De Gorordo A, D'Alessio FR, Kubo K (2009) Acute lung injury review. Intern Med 48(9):621-630

52. Quinlan GJ, Lamb NJ, Tilley R, Evans TW, Gutteridge JM (1997) Plasma hypoxanthine levels in ARDS: implications for oxidative stress, morbidity, and mortality. Am J Respir Crit Care Med 155(2):479-484 
53. Kellner M, Noonepalle S, Lu Q, Srivastava A, Zemskov E, Black SM (2017) ROS signaling in the pathogenesis of acute lung injury (ALI) and acute respiratory distress syndrome (ARDS). Adv Exp Med Biol 967:105-137

54. Martinez FJ, Collard HR, Pardo A, Raghu G, Richeldi L, Selman M et al (2017) Idiopathic pulmonary fibrosis. Nat Rev Dis Primers 3:17074

55. Hecker L, Logsdon NJ, Kurundkar D, Kurundkar A, Bernard K, Hock T et al (2014) Reversal of persistent fibrosis in aging by targeting Nox4-Nrf2 redox imbalance. Sci Transl Med 6(231):231 ra47

56. Ciencewicki J, Trivedi S, Kleeberger SR (2008) Oxidants and the pathogenesis of lung diseases. J Allergy Clin Immunol 122(3):456-468. quiz 69-70

57. Fruhwirth GO, Loidl A, Hermetter A (2007) Oxidized phospholipids: from molecular properties to disease. Biochim Biophys Acta 1772(7):718-736

58. Freigang $S$ (2016) The regulation of inflammation by oxidized phospholipids. Eur J Immunol 46(8): $1818-1825$

59. Awasthi YC, Sharma R, Cheng JZ, Yang Y, Sharma A, Singhal SS et al (2003) Role of 4-hydroxynonenal in stress-mediated apoptosis signaling. Mol Aspects Med 24(4-5):219-230

60. Breitzig M, Bhimineni C, Lockey R, Kolliputi N (2016) 4-Hydroxy-2-nonenal: a critical target in oxidative stress? Am J Physiol Cell Physiol 311(4):C537-CC43

61. Kagan VE, Mao G, Qu F, Angeli JP, Doll S, Croix CS et al (2017) Oxidized arachidonic and adrenic PEs navigate cells to ferroptosis. Nat Chem Biol 13(1):81-90

62. Karki P, Meliton A, Shah A, Tian Y, Ohmura T, Sarich N et al (2018) Role of truncated oxidized phospholipids in acute endothelial barrier dysfunction caused by particulate matter. PLoS One 13(11):e0206251

63. Imai Y, Kuba K, Neely GG, Yaghubian-Malhami R, Perkmann T, van Loo G et al (2008) Identification of oxidative stress and toll-like receptor 4 signaling as a key pathway of acute lung injury. Cell 133(2):235-249

64. Romero F, Shah D, Duong M, Penn RB, Fessler MB, Madenspacher J et al (2015) A pneumocyte-macrophage paracrine lipid axis drives the lung toward fibrosis. Am J Respir Cell Mol Biol 53(1):74-86

65. Almstrand AC, Voelker D, Murphy RC (2015) Identification of oxidized phospholipids in bronchoalveolar lavage exposed to low ozone levels using multivariate analysis. Anal Biochem 474:50-58

66. Lenz AG, Jorens PG, Meyer B, De Backer W, Van Overveld F, Bossaert L et al (1999) Oxidatively modified proteins in bronchoalveolar lavage fluid of patients with ARDS and patients at-risk for ARDS. Eur Respir J 13(1):169-174

67. Rahman I, van Schadewijk AA, Crowther AJ, Hiemstra PS, Stolk J, MacNee W et al (2002) 4-Hydroxy-2-nonenal, a specific lipid peroxidation product, is elevated in lungs of patients with chronic obstructive pulmonary disease. Am J Respir Crit Care Med 166(4):490-495

68. Paliogiannis P, Fois AG, Collu C, Bandinu A, Zinellu E, Carru C et al (2018) Oxidative stresslinked biomarkers in idiopathic pulmonary fibrosis: a systematic review and meta-analysis. Biomark Med 12(10): 1175-1184

69. Rogers LK, Cismowski MJ (2018) Oxidative stress in the lung - the essential paradox. Curr Opin Toxicol 7:37-43

70. Gill R, Tsung A, Billiar T (2010) Linking oxidative stress to inflammation: toll-like receptors. Free Radic Biol Med 48(9):1121-1132

71. Akira S, Takeda K (2004) Toll-like receptor signalling. Nat Rev Immunol 4(7):499-511

72. Kong X, Thimmulappa R, Craciun F, Harvey C, Singh A, Kombairaju P et al (2011) Enhancing Nrf2 pathway by disruption of Keap1 in myeloid leukocytes protects against sepsis. Am J Respir Crit Care Med 184(8):928-938

73. Tawadros PS, Powers KA, Ailenberg M, Birch SE, Marshall JC, Szaszi K et al (2015) Oxidative stress increases surface toll-like receptor 4 expression in murine macrophages via ceramide generation. Shock 44(2):157-165 
74. Kong X, Thimmulappa R, Kombairaju P, Biswal S (2010) NADPH oxidase-dependent reactive oxygen species mediate amplified TLR4 signaling and sepsis-induced mortality in Nrf2deficient mice. J Immunol 185(1):569-577

75. Nakahira K, Kim HP, Geng XH, Nakao A, Wang X, Murase N et al (2006) Carbon monoxide differentially inhibits TLR signaling pathways by regulating ROS-induced trafficking of TLRs to lipid rafts. J Exp Med 203(10):2377-2389

76. Jarman ER, Khambata VS, Cope C, Jones P, Roger J, Ye LY et al (2014) An inhibitor of NADPH oxidase-4 attenuates established pulmonary fibrosis in a rodent disease model. Am J Respir Cell Mol Biol 50(1):158-169

77. Han W, Li H, Cai J, Gleaves LA, Polosukhin VV, Segal BH et al (2013) NADPH oxidase limits lipopolysaccharide-induced lung inflammation and injury in mice through reductionoxidation regulation of NF- $\mathrm{KB}$ activity. J Immunol 190(9):4786-4794

78. Zhang WJ, Wei H, Tien YT, Frei B (2011) Genetic ablation of phagocytic NADPH oxidase in mice limits TNF $\alpha$-induced inflammation in the lungs but not other tissues. Free Radic Biol Med 50(11):1517-1525

79. Bagaitkar J, Pech NK, Ivanov S, Austin A, Zeng MY, Pallat S et al (2015) NADPH oxidase controls neutrophilic response to sterile inflammation in mice by regulating the IL- $1 \alpha / \mathrm{G}-\mathrm{CSF}$ axis. Blood 126(25):2724-2733

80. West AP, Brodsky IE, Rahner C, Woo DK, Erdjument-Bromage H, Tempst P et al (2011) TLR signalling augments macrophage bactericidal activity through mitochondrial ROS. Nature 472(7344):476-480

81. Bulua AC, Simon A, Maddipati R, Pelletier M, Park H, Kim KY et al (2011) Mitochondrial reactive oxygen species promote production of proinflammatory cytokines and are elevated in TNFR1-associated periodic syndrome (TRAPS). J Exp Med 208(3):519-533

82. Wang MM, Lu M, Zhang CL, Wu X, Chen JX, Lv WW et al (2018) Oxidative stress modulates the expression of toll-like receptor 3 during respiratory syncytial virus infection in human lung epithelial A549 cells. Mol Med Rep 18(2):1867-1877

83. Que X, Hung MY, Yeang C, Gonen A, Prohaska TA, Sun X et al (2018) Oxidized phospholipids are proinflammatory and proatherogenic in hypercholesterolaemic mice. Nature 558(7709):301-306

84. Chu LH, Indramohan M, Ratsimandresy RA, Gangopadhyay A, Morris EP, Monack DM et al (2018) The oxidized phospholipid oxPAPC protects from septic shock by targeting the noncanonical inflammasome in macrophages. Nat Commun 9(1):996

85. Sapkota M, DeVasure JM, Kharbanda KK, Wyatt TA (2017) Malondialdehyde-acetaldehyde (MAA) adducted surfactant protein induced lung inflammation is mediated through scavenger receptor a (SR-A1). Respir Res 18(1):36

86. Wyatt TA, Kharbanda KK, McCaskill ML, Tuma DJ, Yanov D, DeVasure J et al (2012) Malondialdehyde-acetaldehyde-adducted protein inhalation causes lung injury. Alcohol 46(1):51-59

87. Guo CJ, Atochina-Vasserman EN, Abramova E, Foley JP, Zaman A, Crouch E et al (2008) S-nitrosylation of surfactant protein-D controls inflammatory function. PLoS Biol 6(11):e266

88. Lingappan K (2018) NF-кB in oxidative stress. Curr Opin Toxicol 7:81-86

89. Korn SH, Wouters EF, Vos N, Janssen-Heininger YM (2001) Cytokine-induced activation of nuclear factor-kappa $\mathrm{B}$ is inhibited by hydrogen peroxide through oxidative inactivation of IkappaB kinase. J Biol Chem 276(38):35693-35700

90. Kamata H, Manabe T, Oka S, Kamata K, Hirata H (2002) Hydrogen peroxide activates IkappaB kinases through phosphorylation of serine residues in the activation loops. FEBS Lett 519(1-3):231-237

91. Li Q, Engelhardt JF (2006) Interleukin-1 beta induction of NFkappaB is partially regulated by H2O2-mediated activation of NFkappaB-inducing kinase. J Biol Chem 281(3):1495-1505

92. Reynaert NL, Ckless K, Korn SH, Vos N, Guala AS, Wouters EF et al (2004) Nitric oxide represses inhibitory kappaB kinase through S-nitrosylation. Proc Natl Acad Sci U S A 101(24):8945-8950 
93. Seldon MP, Silva G, Pejanovic N, Larsen R, Gregoire IP, Filipe J et al (2007) Heme oxygenase-1 inhibits the expression of adhesion molecules associated with endothelial cell activation via inhibition of NF-kappaB RelA phosphorylation at serine 276. J Immunol 179(11):7840-7851

94. Kelleher ZT, Sha Y, Foster MW, Foster WM, Forrester MT, Marshall HE (2014) Thioredoxinmediated denitrosylation regulates cytokine-induced nuclear factor $\mathrm{\kappa B}(\mathrm{NF}-\mathrm{\kappa B})$ activation. J Biol Chem 289(5):3066-3072

95. Wu M, Bian Q, Liu Y, Fernandes AF, Taylor A, Pereira P et al (2009) Sustained oxidative stress inhibits NF-kappaB activation partially via inactivating the proteasome. Free Radic Biol Med 46(1):62-69

96. Oka S, Kamata H, Kamata K, Yagisawa H, Hirata H (2000) N-acetylcysteine suppresses TNF-induced NF-kappaB activation through inhibition of IkappaB kinases. FEBS Lett 472(2-3): 196-202

97. Thimmulappa RK, Lee H, Rangasamy T, Reddy SP, Yamamoto M, Kensler TW et al (2006) $\mathrm{Nrf2}$ is a critical regulator of the innate immune response and survival during experimental sepsis. J Clin Invest 116(4):984-995

98. Thimmulappa RK, Scollick C, Traore K, Yates M, Trush MA, Liby KT et al (2006) Nrf2dependent protection from LPS induced inflammatory response and mortality by CDDOImidazolide. Biochem Biophys Res Commun 351(4):883-889

99. Howrylak JA, Nakahira K (2017) Inflammasomes: key mediators of lung immunity. Annu Rev Physiol 79:471-494

100. Pinkerton JW, Kim RY, Robertson AAB, Hirota JA, Wood LG, Knight DA et al (2017) Inflammasomes in the lung. Mol Immunol 86:44-55

101. Abais JM, Xia M, Zhang Y, Boini KM, Li PL (2015) Redox regulation of NLRP3 inflammasomes: ROS as trigger or effector? Antioxid Redox Signal 22(13):1111-1129

102. Abais JM, Zhang C, Xia M, Liu Q, Gehr TW, Boini KM et al (2013) NADPH oxidasemediated triggering of inflammasome activation in mouse podocytes and glomeruli during hyperhomocysteinemia. Antioxid Redox Signal 18(13):1537-1548

103. Wu J, Yan Z, Schwartz DE, Yu J, Malik AB, Hu G (2013) Activation of NLRP3 inflammasome in alveolar macrophages contributes to mechanical stretch-induced lung inflammation and injury. J Immunol 190(7):3590-3599

104. Zhou R, Tardivel A, Thorens B, Choi I, Tschopp J (2010) Thioredoxin-interacting protein links oxidative stress to inflammasome activation. Nat Immunol 11(2):136-140

105. Buskiewicz IA, Montgomery T, Yasewicz EC, Huber SA, Murphy MP, Hartley RC et al (2016) Reactive oxygen species induce virus-independent MAVS oligomerization in systemic lupus erythematosus. Sci Signal 9(456):ra115

106. Marumo S, Hoshino Y, Kiyokawa H, Tanabe N, Sato A, Ogawa E et al (2014) p38 mitogenactivated protein kinase determines the susceptibility to cigarette smoke-induced emphysema in mice. BMC Pulm Med 14:79

107. Sivanantham A, Pattarayan D, Bethunaickan R, Kar A, Mahapatra SK, Thimmulappa RK et al (2019) Tannic acid protects against experimental acute lung injury through downregulation of TLR4 and MAPK. J Cell Physiol 234(5):6463-6476

108. Cuenda A, Rousseau S (2007) p38 MAP-kinases pathway regulation, function and role in human diseases. Biochim Biophys Acta 1773(8):1358-1375

109. Lee K, Esselman WJ (2002) Inhibition of PTPs by $\mathrm{H}(2) \mathrm{O}(2)$ regulates the activation of distinct MAPK pathways. Free Radic Biol Med 33(8):1121-1132

110. Lin B, Xu J, Feng DG, Wang F, Wang JX, Zhao H (2018) DUSP14 knockout accelerates cardiac ischemia reperfusion (IR) injury through activating NF- $\mathrm{KB}$ and MAPKs signaling pathways modulated by ROS generation. Biochem Biophys Res Commun 501(1):24-32

111. Chopra P, Kanoje V, Semwal A, Ray A (2008) Therapeutic potential of inhaled p38 mitogenactivated protein kinase inhibitors for inflammatory pulmonary diseases. Expert Opin Investig Drugs 17(10):1411-1425

112. Franklin JL (2011) Redox regulation of the intrinsic pathway in neuronal apoptosis. Antioxid Redox Signal 14(8):1437-1448 
113. Martin TR, Nakamura M, Matute-Bello G (2003) The role of apoptosis in acute lung injury. Crit Care Med 31(4 Suppl):S184-S188

114. Ayala A, Muñoz MF, Argüelles S (2014) Lipid peroxidation: production, metabolism, and signaling mechanisms of malondialdehyde and 4-hydroxy-2-nonenal. Oxid Med Cell Longev 2014:360438

115. Choudhary S, Zhang W, Zhou F, Campbell GA, Chan LL, Thompson EB et al (2002) Cellular lipid peroxidation end-products induce apoptosis in human lens epithelial cells. Free Radic Biol Med 32(4):360-369

116. Kruman II, Mattson MP (1999) Pivotal role of mitochondrial calcium uptake in neural cell apoptosis and necrosis. J Neurochem 72(2):529-540

117. Lee H, Park JR, Kim EJ, Kim WJ, Hong SH, Park SM et al (2016) Cigarette smoke-mediated oxidative stress induces apoptosis via the MAPKs/STAT1 pathway in mouse lung fibroblasts. Toxicol Lett 240(1):140-148

118. Harvey CJ, Thimmulappa RK, Singh A, Blake DJ, Ling G, Wakabayashi N et al (2009) Nrf2regulated glutathione recycling independent of biosynthesis is critical for cell survival during oxidative stress. Free Radic Biol Med 46(4):443-453

119. Prakash YS, Pabelick CM, Sieck GC (2017) Mitochondrial dysfunction in airway disease. Chest 152(3):618-626

120. Wiegman CH, Michaeloudes C, Haji G, Narang P, Clarke CJ, Russell KE et al (2015) Oxidative stress-induced mitochondrial dysfunction drives inflammation and airway smooth muscle remodeling in patients with chronic obstructive pulmonary disease. J Allergy Clin Immunol 136(3):769-780

121. Liu X, Chen Z (2017) The pathophysiological role of mitochondrial oxidative stress in lung diseases. J Transl Med 15(1):207

122. Hoffmann RF, Zarrintan S, Brandenburg SM, Kol A, de Bruin HG, Jafari S et al (2013) Prolonged cigarette smoke exposure alters mitochondrial structure and function in airway epithelial cells. Respir Res 14:97

123. Rabinovich RA, Bastos R, Ardite E, Llinàs L, Orozco-Levi M, Gea J et al (2007) Mitochondrial dysfunction in COPD patients with low body mass index. Eur Respir J 29(4):643-650

124. Mabalirajan U, Dinda AK, Sharma SK, Ghosh B (2009) Esculetin restores mitochondrial dysfunction and reduces allergic asthma features in experimental murine model. J Immunol 183(3):2059-2067

125. Mabalirajan U, Dinda AK, Kumar S, Roshan R, Gupta P, Sharma SK et al (2008) Mitochondrial structural changes and dysfunction are associated with experimental allergic asthma. J Immunol 181(5):3540-3548

126. Athale J, Ulrich A, MacGarvey NC, Bartz RR, Welty-Wolf KE, Suliman HB et al (2012) Nrf2 promotes alveolar mitochondrial biogenesis and resolution of lung injury in Staphylococcus aureus pneumonia in mice. Free Radic Biol Med 53(8):1584-1594

127. Trian T, Benard G, Begueret H, Rossignol R, Girodet PO, Ghosh D et al (2007) Bronchial smooth muscle remodeling involves calcium-dependent enhanced mitochondrial biogenesis in asthma. J Exp Med 204(13):3173-3181

128. Araya J, Tsubouchi K, Sato N, Ito S, Minagawa S, Hara H et al (2018) PRKN-regulated mitophagy and cellular senescence during COPD pathogenesis. Autophagy:1-17

129. Ahmad T, Sundar IK, Lerner CA, Gerloff J, Tormos AM, Yao H et al (2015) Impaired mitophagy leads to cigarette smoke stress-induced cellular senescence: implications for chronic obstructive pulmonary disease. FASEB J 29(7):2912-2929

130. Chilosi M, Carloni A, Rossi A, Poletti V (2013) Premature lung aging and cellular senescence in the pathogenesis of idiopathic pulmonary fibrosis and COPD/emphysema. Transl Res 162(3): 156-173

131. Aravamudan B, Kiel A, Freeman M, Delmotte P, Thompson M, Vassallo R et al (2014) Cigarette smoke-induced mitochondrial fragmentation and dysfunction in human airway smooth muscle. Am J Physiol Lung Cell Mol Physiol 306(9):L840-L854

132. Bueno M, Lai YC, Romero Y, Brands J, St Croix CM, Kamga C et al (2015) PINK1 deficiency impairs mitochondrial homeostasis and promotes lung fibrosis. J Clin Invest 125(2):521-538 
133. Chen BB, Coon TA, Glasser JR, Zou C, Ellis B, Das T et al (2014) E3 ligase subunit Fbxo15 and PINK1 kinase regulate cardiolipin synthase 1 stability and mitochondrial function in pneumonia. Cell Rep 7(2):476-487

134. Tait SW, Green DR (2013) Mitochondrial regulation of cell death. Cold Spring Harb Perspect Biol:5(9)

135. Schumacker PT, Gillespie MN, Nakahira K, Choi AM, Crouser ED, Piantadosi CA et al (2014) Mitochondria in lung biology and pathology: more than just a powerhouse. Am J Physiol Lung Cell Mol Physiol 306(11):L962-L974

136. Szczesny B, Marcatti M, Ahmad A, Montalbano M, Brunyánszki A, Bibli SI et al (2018) Mitochondrial DNA damage and subsequent activation of Z-DNA binding protein 1 links oxidative stress to inflammation in epithelial cells. Sci Rep 8(1):914

137. Krychtiuk KA, Ruhittel S, Hohensinner PJ, Koller L, Kaun C, Lenz M et al (2015) Mitochondrial DNA and toll-like Receptor-9 are associated with mortality in critically ill patients. Crit Care Med 43(12):2633-2641

138. McDonald B, Pittman K, Menezes GB, Hirota SA, Slaba I, Waterhouse CC et al (2010) Intravascular danger signals guide neutrophils to sites of sterile inflammation. Science 330(6002):362-366

139. Lommatzsch M, Cicko S, Müller T, Lucattelli M, Bratke K, Stoll P et al (2010) Extracellular adenosine triphosphate and chronic obstructive pulmonary disease. Am J Respir Crit Care Med 181(9):928-934

140. Idzko M, Hammad H, van Nimwegen M, Kool M, Willart MA, Muskens F et al (2007) Extracellular ATP triggers and maintains asthmatic airway inflammation by activating dendritic cells. Nat Med 13(8):913-919

141. Riteau N, Gasse P, Fauconnier L, Gombault A, Couegnat M, Fick L et al (2010) Extracellular ATP is a danger signal activating P2X7 receptor in lung inflammation and fibrosis. Am J Respir Crit Care Med 182(6):774-783

142. Dudek J (2017) Role of Cardiolipin in mitochondrial signaling pathways. Front Cell Dev Biol 5:90

143. Ray NB, Durairaj L, Chen BB, McVerry BJ, Ryan AJ, Donahoe M et al (2010) Dynamic regulation of cardiolipin by the lipid pump Atp8b1 determines the severity of lung injury in experimental pneumonia. Nat Med 16(10):1120-1127

144. Jain M, Rivera S, Monclus EA, Synenki L, Zirk A, Eisenbart J et al (2013) Mitochondrial reactive oxygen species regulate transforming growth factor- $\beta$ signaling. J Biol Chem 288(2):770-777

145. Schröder M, Kaufman RJ (2005) The mammalian unfolded protein response. Annu Rev Biochem 74:739-789

146. Tanjore H, Blackwell TS, Lawson WE (2012) Emerging evidence for endoplasmic reticulum stress in the pathogenesis of idiopathic pulmonary fibrosis. Am J Physiol Lung Cell Mol Physiol 302(8):L721-L729

147. Kim SR, Lee YC (2015) Endoplasmic reticulum stress and the related signaling networks in severe asthma. Allergy Asthma Immunol Res 7(2):106-117

148. Kenche H, Ye ZW, Vedagiri K, Richards DM, Gao XH, Tew KD et al (2016) Adverse outcomes associated with cigarette smoke radicals related to damage to protein-disulfide isomerase. J Biol Chem 291(9):4763-4778

149. Geraghty P, Baumlin N, Salathe MA, Foronjy RF, D'Armiento JM (2016) Glutathione Peroxidase-1 suppresses the unfolded protein response upon cigarette smoke exposure. Mediators Inflamm 2016:9461289

150. Teng RJ, Jing X, Michalkiewicz T, Afolayan AJ, Wu TJ, Konduri GG (2017) Attenuation of endoplasmic reticulum stress by caffeine ameliorates hyperoxia-induced lung injury. Am J Physiol Lung Cell Mol Physiol 312(5):L586-LL98

151. Plaisance V, Brajkovic S, Tenenbaum M, Favre D, Ezanno H, Bonnefond A et al (2016) Endoplasmic reticulum stress links oxidative stress to impaired pancreatic Beta-cell function caused by human oxidized LDL. PLoS One 11(9):e0163046 
152. Bhandary B, Marahatta A, Kim HR, Chae HJ (2012) An involvement of oxidative stress in endoplasmic reticulum stress and its associated diseases. Int J Mol Sci 14(1):434-456

153. Afanas'ev I (2014) New nucleophilic mechanisms of ros-dependent epigenetic modifications: comparison of aging and cancer. Aging Dis 5(1):52-62

154. Kietzmann T, Petry A, Shvetsova A, Gerhold JM, Görlach A (2017) The epigenetic landscape related to reactive oxygen species formation in the cardiovascular system. $\mathrm{Br} \mathrm{J}$ Pharmacol 174(12):1533-1554

155. Mentch SJ, Mehrmohamadi M, Huang L, Liu X, Gupta D, Mattocks D et al (2015) Histone methylation dynamics and gene regulation occur through the sensing of one-carbon metabolism. Cell Metab 22(5):861-873

156. Cyr AR, Domann FE (2011) The redox basis of epigenetic modifications: from mechanisms to functional consequences. Antioxid Redox Signal 15(2):551-589

157. Mercado N, Thimmulappa R, Thomas CM, Fenwick PS, Chana KK, Donnelly LE et al (2011) Decreased histone deacetylase 2 impairs Nrf2 activation by oxidative stress. Biochem Biophys Res Commun 406(2):292-298

158. Osoata GO, Yamamura S, Ito M, Vuppusetty C, Adcock IM, Barnes PJ et al (2009) Nitration of distinct tyrosine residues causes inactivation of histone deacetylase 2. Biochem Biophys Res Commun 384(3):366-371

159. Barnes PJ, Ito K, Adcock IM (2004) Corticosteroid resistance in chronic obstructive pulmonary disease: inactivation of histone deacetylase. Lancet 363(9410):731-733

160. Lin Y, Liu X, Cheng Y, Yang J, Huo Y, Zhang C (2009) Involvement of MicroRNAs in hydrogen peroxide-mediated gene regulation and cellular injury response in vascular smooth muscle cells. J Biol Chem 284(12):7903-7913

161. Emde A, Hornstein E (2014) miRNAs at the interface of cellular stress and disease. EMBO J 33(13):1428-1437

162. Potteti HR, Rajasekaran S, Rajamohan SB, Tamatam CR, Reddy NM, Reddy SP (2016) Sirtuin 1 promotes Hyperoxia-induced lung epithelial cell death independent of NF-E2related factor 2 activation. Am J Respir Cell Mol Biol 54(5):697-706

163. Breton CV, Salam MT, Wang X, Byun HM, Siegmund KD, Gilliland FD (2012) Particulate matter, DNA methylation in nitric oxide synthase, and childhood respiratory disease. Environ Health Perspect 120(9):1320-1326

164. Yang IV, Schwartz DA (2015) Epigenetics of idiopathic pulmonary fibrosis. Transl Res 165(1):48-60

165. Richter K, Konzack A, Pihlajaniemi T, Heljasvaara R, Kietzmann T (2015) Redox-fibrosis: impact of TGF $\beta 1$ on ROS generators, mediators and functional consequences. Redox Biol 6:344-352

166. Liu RM, Desai LP (2015) Reciprocal regulation of TGF- $\beta$ and reactive oxygen species: a perverse cycle for fibrosis. Redox Biol 6:565-577

167. Chan EC, Peshavariya HM, Liu GS, Jiang F, Lim SY, Dusting GJ (2013) Nox4 modulates collagen production stimulated by transforming growth factor $\beta 1$ in vivo and in vitro. Biochem Biophys Res Commun 430(3):918-925

168. Nakano H, Nakajima A, Sakon-Komazawa S, Piao JH, Xue X, Okumura K (2006) Reactive oxygen species mediate crosstalk between NF-kappaB and JNK. Cell Death Differ 13(5):730-737

169. Carnesecchi S, Deffert C, Donati Y, Basset O, Hinz B, Preynat-Seauve O et al (2011) A key role for NOX4 in epithelial cell death during development of lung fibrosis. Antioxid Redox Signal 15(3):607-619

170. Leask A (2013) Integrin. Adv Wound Care (New Rochelle) 2(4):160-166

171. Waisberg DR, Barbas-Filho JV, Parra ER, Fernezlian S, de Carvalho CR, Kairalla RA et al (2010) Abnormal expression of telomerase/apoptosis limits type II alveolar epithelial cell replication in the early remodeling of usual interstitial pneumonia/idiopathic pulmonary fibrosis. Hum Pathol 41(3):385-391 
172. Bocchino M, Agnese S, Fagone E, Svegliati S, Grieco D, Vancheri C et al (2010) Reactive oxygen species are required for maintenance and differentiation of primary lung fibroblasts in idiopathic pulmonary fibrosis. PLoS One 5(11):e14003

173. Button B, Anderson WH, Boucher RC (2016) Mucus Hyperconcentration as a unifying aspect of the chronic Bronchitic phenotype. Ann Am Thorac Soc 13(Suppl 2):S156-S162

174. Ridley C, Thornton DJ (2018) Mucins: the frontline defence of the lung. Biochem Soc Trans 46(5):1099-1106

175. Kim HJ, Park YD, Moon UY, Kim JH, Jeon JH, Lee JG et al (2008) The role of Nox4 in oxidative stress-induced MUC5AC overexpression in human airway epithelial cells. Am J Respir Cell Mol Biol 39(5):598-609

176. Takeyama K, Dabbagh K, Jeong Shim J, Dao-Pick T, Ueki IF, Nadel JA (2000) Oxidative stress causes mucin synthesis via transactivation of epidermal growth factor receptor: role of neutrophils. J Immunol 164(3):1546-1552

177. Rose MC, Voynow JA (2006) Respiratory tract mucin genes and mucin glycoproteins in health and disease. Physiol Rev 86(1):245-278

178. Kim KC (2012) Role of epithelial mucins during airway infection. Pulm Pharmacol Ther 25(6):415-419

179. Shao MX, Nadel JA (2005) Dual oxidase 1-dependent MUC5AC mucin expression in cultured human airway epithelial cells. Proc Natl Acad Sci U S A 102(3):767-772

180. Yu H, Li Q, Zhou X, Kolosov VP, Perelman JM (2011) Role of hyaluronan and CD44 in reactive oxygen species-induced mucus hypersecretion. Mol Cell Biochem 352(1-2):65-75

181. Darcan-Nicolaisen Y, Meinicke H, Fels G, Hegend O, Haberland A, Kühl A et al (2009) Small interfering RNA against transcription factor STAT6 inhibits allergic airway inflammation and hyperreactivity in mice. J Immunol 182(12):7501-7508

182. Cantin AM, North SL, Hubbard RC, Crystal RG (1987) Normal alveolar epithelial lining fluid contains high levels of glutathione. J Appl Physiol (1985) 63(1):152-157

183. Cantin AM, Hubbard RC, Crystal RG (1989) Glutathione deficiency in the epithelial lining fluid of the lower respiratory tract in idiopathic pulmonary fibrosis. Am Rev Respir Dis 139(2):370-372

184. Gould NS, Day BJ (2011) Targeting maladaptive glutathione responses in lung disease. Biochem Pharmacol 81(2):187-193

185. Qanungo S, Starke DW, Pai HV, Mieyal JJ, Nieminen AL (2007) Glutathione supplementation potentiates hypoxic apoptosis by S-glutathionylation of p65-NFkappaB. J Biol Chem 282(25): $18427-18436$

186. Reynaert NL, van der Vliet A, Guala AS, McGovern T, Hristova M, Pantano C et al (2006) Dynamic redox control of NF-kappaB through glutaredoxin-regulated S-glutathionylation of inhibitory kappaB kinase beta. Proc Natl Acad Sci U S A 103(35):13086-13091

187. Panda K, Chattopadhyay R, Ghosh MK, Chattopadhyay DJ, Chatterjee IB (1999) Vitamin $\mathrm{C}$ prevents cigarette smoke induced oxidative damage of proteins and increased proteolysis. Free Radic Biol Med 27(9-10):1064-1079

188. Crobeddu B, Aragao-Santiago L, Bui LC, Boland S, Baeza SA (2017) Oxidative potential of particulate matter 2.5 as predictive indicator of cellular stress. Environ Pollut 230:125-133

189. Wu F, Schuster DP, Tyml K, Wilson JX (2007) Ascorbate inhibits NADPH oxidase subunit p47phox expression in microvascular endothelial cells. Free Radic Biol Med 42(1):124-131

190. Kelly FJ, Tetley TD (1997) Nitrogen dioxide depletes uric acid and ascorbic acid but not glutathione from lung lining fluid. Biochem J 325(Pt 1):95-99

191. Mudway IS, Krishna MT, Frew AJ, MacLeod D, Sandstrom T, Holgate ST et al (1999) Compromised concentrations of ascorbate in fluid lining the respiratory tract in human subjects after exposure to ozone. Occup Environ Med 56(7):473-481

192. Gupta I, Ganguly S, Rozanas CR, Stuehr DJ, Panda K (2016) Ascorbate attenuates pulmonary emphysema by inhibiting tobacco smoke and Rtp801-triggered lung protein modification and proteolysis. Proc Natl Acad Sci U S A 113(29):E4208-E4217

193. Kelly FJ, Mudway I, Blomberg A, Frew A, Sandström T (1999) Altered lung antioxidant status in patients with mild asthma. Lancet 354(9177):482-483 
194. Kongerud J, Crissman K, Hatch G, Alexis N (2003) Ascorbic acid is decreased in induced sputum of mild asthmatics. Inhal Toxicol 15(2):101-109

195. Wilkinson M, Hart A, Milan SJ, Sugumar K (2014) Vitamins C and E for asthma and exerciseinduced bronchoconstriction. Cochrane Database Syst Rev 6:CD010749

196. Behndig AF, Blomberg A, Helleday R, Kelly FJ, Mudway IS (2009) Augmentation of respiratory tract lining fluid ascorbate concentrations through supplementation with vitamin $\mathrm{C}$. Inhal Toxicol 21(3):250-258

197. Peden DB, Hohman R, Brown ME, Mason RT, Berkebile C, Fales HM et al (1990) Uric acid is a major antioxidant in human nasal airway secretions. Proc Natl Acad Sci U S A 87(19):7638-7642

198. Peden DB, Swiersz M, Ohkubo K, Hahn B, Emery B, Kaliner MA (1993) Nasal secretion of the ozone scavenger uric acid. Am Rev Respir Dis 148(2):455-461

199. Kelly FJ, Blomberg A, Frew A, Holgate ST, Sandstrom T (1996) Antioxidant kinetics in lung lavage fluid following exposure of humans to nitrogen dioxide. Am J Respir Crit Care Med 154(6 Pt 1):1700-1705

200. Kahnert K, Alter P, Welte T, Huber RM, Behr J, Biertz F et al (2018) Uric acid, lung function, physical capacity and exacerbation frequency in patients with COPD: a multi-dimensional approach. Respir Res 19(1):110

201. Horsfall LJ, Nazareth I, Petersen I (2014) Serum uric acid and the risk of respiratory disease: a population-based cohort study. Thorax 69(11):1021-1026

202. Guertin KA, Grant RK, Arnold KB, Burwell L, Hartline J, Goodman PJ et al (2016) Effect of long-term vitamin $\mathrm{E}$ and selenium supplementation on urine F2-isoprostanes, a biomarker of oxidative stress. Free Radic Biol Med 95:349-356

203. Hanson C, Lyden E, Furtado J, Campos H, Sparrow D, Vokonas P et al (2016) Serum tocopherol levels and vitamin $\mathrm{E}$ intake are associated with lung function in the normative aging study. Clin Nutr 35(1):169-174

204. Burbank AJ, Duran CG, Pan Y, Burns P, Jones S, Jiang Q et al (2018) Gamma tocopherolenriched supplement reduces sputum eosinophilia and endotoxin-induced sputum neutrophilia in volunteers with asthma. J Allergy Clin Immunol 141(4):1231-8.e1

205. Peh HY, Tan WSD, Chan TK, Pow CW, Foster PS, Wong WSF (2017) Vitamin E isoform $\gamma$-tocotrienol protects against emphysema in cigarette smoke-induced COPD. Free Radic Biol Med 110:332-344

206. Pearson PJ, Lewis SA, Britton J, Fogarty A (2004) Vitamin E supplements in asthma: a parallel group randomised placebo controlled trial. Thorax 59(8):652-656

207. Bridges JP, Davis HW, Damodarasamy M, Kuroki Y, Howles G, Hui DY et al (2000) Pulmonary surfactant proteins a and D are potent endogenous inhibitors of lipid peroxidation and oxidative cellular injury. J Biol Chem 275(49):38848-38855

208. Laucho-Contreras ME, Polverino F, Tesfaigzi Y, Pilon A, Celli BR, Owen CA (2016) Club cell protein 16 (CC16) augmentation: a potential disease-modifying approach for chronic obstructive pulmonary disease (COPD). Expert Opin Ther Targets 20(7):869-883

209. Laucho-Contreras ME, Polverino F, Gupta K, Taylor KL, Kelly E, Pinto-Plata V et al (2015) Protective role for club cell secretory protein-16 (CC16) in the development of COPD. Eur Respir J 45(6):1544-1556

210. Guerra S, Halonen M, Vasquez MM, Spangenberg A, Stern DA, Morgan WJ et al (2015) Relation between circulating CC16 concentrations, lung function, and development of chronic obstructive pulmonary disease across the lifespan: a prospective study. Lancet Respir Med 3(8):613-620

211. Lam DC, Kwok HH, Yu WC, Ko FW, Tam CY, Lau AC et al (2018) CC16 levels correlate with cigarette smoke exposure in bronchial epithelial cells and with lung function decline in smokers. BMC Pulm Med 18(1):47

212. Rahman I, MacNee W (2012) Antioxidant pharmacological therapies for COPD. Curr Opin Pharmacol 12(3):256-265

213. Bargagli E, Olivieri C, Bennett D, Prasse A, Muller-Quernheim J, Rottoli P (2009) Oxidative stress in the pathogenesis of diffuse lung diseases: a review. Respir Med 103(9):1245-1256 
214. Gao F, Kinnula VL, Myllärniemi M, Oury TD (2008) Extracellular superoxide dismutase in pulmonary fibrosis. Antioxid Redox Signal 10(2):343-354

215. Yao H, Arunachalam G, Hwang JW, Chung S, Sundar IK, Kinnula VL et al (2010) Extracellular superoxide dismutase protects against pulmonary emphysema by attenuating oxidative fragmentation of ECM. Proc Natl Acad Sci U S A 107(35):15571-15576

216. Foronjy RF, Mirochnitchenko O, Propokenko O, Lemaitre V, Jia Y, Inouye M et al (2006) Superoxide dismutase expression attenuates cigarette smoke- or elastase-generated emphysema in mice. Am J Respir Crit Care Med 173(6):623-631

217. Comhair SA, Ricci KS, Arroliga M, Lara AR, Dweik RA, Song W et al (2005) Correlation of systemic superoxide dismutase deficiency to airflow obstruction in asthma. Am J Respir Crit Care Med 172(3):306-313

218. Comhair SA, Bhathena PR, Dweik RA, Kavuru M, Erzurum SC (2000) Rapid loss of superoxide dismutase activity during antigen-induced asthmatic response. Lancet 355(9204):624

219. Dittrich AM, Meyer HA, Krokowski M, Quarcoo D, Ahrens B, Kube SM et al (2010) Glutathione peroxidase-2 protects from allergen-induced airway inflammation in mice. Eur Respir J 35(5): 1148-1154

220. Kunwar A, Haston CK (2014) Basal levels of glutathione peroxidase correlate with onset of radiation induced lung disease in inbred mouse strains. Am J Physiol Lung Cell Mol Physiol 307(8):L597-L604

221. Kinnula VL, Lehtonen S, Kaarteenaho-Wiik R, Lakari E, Pääkkö P, Kang SW et al (2002) Cell specific expression of peroxiredoxins in human lung and pulmonary sarcoidosis. Thorax 57(2): 157-164

222. Ryter SW, Choi AM (2009) Heme oxygenase-1/carbon monoxide: from metabolism to molecular therapy. Am J Respir Cell Mol Biol 41(3):251-260

223. Duckers HJ, Boehm M, True AL, Yet SF, San H, Park JL et al (2001) Heme oxygenase-1 protects against vascular constriction and proliferation. Nat Med 7(6):693-698

224. Zampetaki A, Minamino T, Mitsialis SA, Kourembanas S (2003) Effect of heme oxygenase-1 overexpression in two models of lung inflammation. Exp Biol Med (Maywood) 228(5):442-446

225. Otterbein LE, Kolls JK, Mantell LL, Cook JL, Alam J, Choi AM (1999) Exogenous administration of heme oxygenase-1 by gene transfer provides protection against hyperoxia-induced lung injury. J Clin Invest 103(7):1047-1054

226. Yamamoto M, Kensler TW, Motohashi H (2018) The KEAP1-NRF2 system: a thiol-based sensor-effector apparatus for maintaining redox homeostasis. Physiol Rev 98(3):1169-1203

227. Cullinan SB, Gordan JD, Jin J, Harper JW, Diehl JA (2004) The Keap1-BTB protein is an adaptor that bridges Nrf2 to a Cul3-based E3 ligase: oxidative stress sensing by a Cul3-Keap1 ligase. Mol Cell Biol 24(19):8477-8486

228. Tong KI, Katoh Y, Kusunoki H, Itoh K, Tanaka T, Yamamoto M (2006) Keap1 recruits Neh2 through binding to ETGE and DLG motifs: characterization of the two-site molecular recognition model. Mol Cell Biol 26(8):2887-2900

229. Rangasamy T, Guo J, Mitzner WA, Roman J, Singh A, Fryer AD et al (2005) Disruption of Nrf2 enhances susceptibility to severe airway inflammation and asthma in mice. J Exp Med 202(1):47-59

230. Cho HY, Reddy SP, Yamamoto M, Kleeberger SR (2004) The transcription factor NRF2 protects against pulmonary fibrosis. FASEB J 18(11):1258-1260

231. Kensler TW, Wakabayashi N, Biswal S (2007) Cell survival responses to environmental stresses via the Keap1-Nrf2-ARE pathway. Annu Rev Pharmacol Toxicol 47:89-116

232. Goven D, Boutten A, Leçon-Malas V, Marchal-Sommé J, Amara N, Crestani B et al (2008) Altered Nrf2/Keap1-Bach1 equilibrium in pulmonary emphysema. Thorax 63(10):916-924

233. Swamy SM, Rajasekaran NS, Thannickal VJ (2016) Nuclear factor-Erythroid-2-related factor 2 in aging and lung fibrosis. Am J Pathol 186(7):1712-1723

234. Espinosa-Diez C, Miguel V, Mennerich D, Kietzmann T, Sánchez-Pérez P, Cadenas S et al (2015) Antioxidant responses and cellular adjustments to oxidative stress. Redox Biol 6:183-197 
235. Grandjean EM, Berthet P, Ruffmann R, Leuenberger P (2000) Efficacy of oral long-term $\mathrm{N}$-acetylcysteine in chronic bronchopulmonary disease: a meta-analysis of published doubleblind, placebo-controlled clinical trials. Clin Ther 22(2):209-221

236. Decramer M, Rutten-van Mölken M, Dekhuijzen PN, Troosters T, van Herwaarden C, Pellegrino R et al (2005) Effects of N-acetylcysteine on outcomes in chronic obstructive pulmonary disease (bronchitis randomized on NAC cost-utility study, BRONCUS): a randomised placebo-controlled trial. Lancet 365(9470):1552-1560

237. Rahman I (2006) Antioxidant therapies in COPD. Int J Chron Obstruct Pulmon Dis 1(1):15-29

238. Brown RH, Reynolds C, Brooker A, Talalay P, Fahey JW (2015) Sulforaphane improves the bronchoprotective response in asthmatics through Nrf2-mediated gene pathways. Respir Res 16:106

239. Wise RA, Holbrook JT, Criner G, Sethi S, Rayapudi S, Sudini KR et al (2016) Lack of effect of Oral Sulforaphane administration on Nrf2 expression in COPD: a randomized, doubleblind, Placebo controlled trial. PLoS One 11(11):e0163716

240. Sudini K, Diette GB, Breysse PN, McCormack MC, Bull D, Biswal S et al (2016) A randomized controlled trial of the effect of broccoli sprouts on antioxidant gene expression and airway inflammation in asthmatics. J Allergy Clin Immunol Pract 4(5):932-940

241. Noah TL, Zhang H, Zhou H, Glista-Baker E, Müller L, Bauer RN et al (2014) Effect of broccoli sprouts on nasal response to live attenuated influenza virus in smokers: a randomized, double-blind study. PLoS One 9(6):e98671

242. Egner PA, Chen JG, Zarth AT, Ng DK, Wang JB, Kensler KH et al (2014) Rapid and sustainable detoxication of airborne pollutants by broccoli sprout beverage: results of a randomized clinical trial in China. Cancer Prev Res (Phila) 7(8):813-823 